\title{
Geosynthetic Engineering and Vegetation Growth in Soil Reinforcement Applications
}

\author{
Daniele Cazzuffi • Giuseppe Cardile • \\ Domenico Gioffrè
}

Accepted: 7 October 2014 / Published online: 16 October 2014

C) Springer New York 2014

\begin{abstract}
In Italy, since early times, the environmental aspects have always been a key issue on the design and the application. Consequently, the geosynthetic reinforced soil structures consist of vegetated face steep slopes. Furthermore, the use of vegetation has also been recognized and incorporated in engineering practice for erosion control and for stabilization of shallow slopes. Vegetation influences slope stability and erosion process by both mechanical effects and hydrological effects. In particular, in the paper, the mechanical effects of vegetation related to soil stabilization will be described. The purpose of this paper is to present the specific role of vegetation in soil reinforcement applications, by means of the analysis of the available literature on the (i) factors affecting root reinforcement of soil, (ii) experimental tests carried out on roots and on roots-soil system, and (iii) analytical and theoretical models. The erosion applications will not treated in this paper. The use of vegetation in civil engineering and landscape works has grown in importance, even if the specific design standard concerning the use of vegetation for slope stabilization is still under discussion. Therefore, design and management of stabilization systems by plants require an accurate knowledge about the quantitative reinforcing root effects on soil strength.
\end{abstract}

Keywords Soil reinforcement - Vegetation growth - Laboratory tests - Root reinforcement

D. Cazzuffi

CESI (Centro elettrotecnico sperimentale italiano), Via Rubattino 54, 20134 Milan, Italy e-mail: daniele.cazzuffi@cesi.it

G. Cardile $(\square) \cdot$ D. Gioffrè $(\square)$

Civil Engineering, Energy, Environment and Materials Department, DICEAM, Mediterranean University of Reggio Calabria, Via Graziella, Località Feo di Vito, 89060 Reggio Calabria, Italy

e-mail: giuseppe.cardile@unirc.it

e-mail: domenico.gioffre@unirc.it 


\section{List of Symbols}

A Specimen area $\left[\mathrm{mm}^{2}\right]$

$A_{\mathrm{R}} \quad$ Cross-sectional area of the root $\left[\mathrm{mm}^{2}\right]$

$d \quad$ Root diameter [mm]

$L_{\mathrm{A}} \quad$ Active length of the root $[\mathrm{mm}]$

$m$ Shear distortion ratio

$N \quad$ Number of roots

PR Pullout force [kN]

RAR Root area ratio $A_{\mathrm{R}} / A$

$T \quad$ Tensile force acting on the root $[\mathrm{kN}]$

$T_{\mathrm{R}} \quad$ Average root tensile strength $[\mathrm{kN}]$

$t_{\mathrm{R}} \quad$ Tensile strength on single root $[\mathrm{Pa}]$

$\Delta c \quad$ Shear strength increment [kPa]

$K \quad$ Correction factor which takes in account the inclination of the roots crossing the shear plane

$\alpha \quad$ Empirical constant to evaluate tensile strength on single root

$\beta \quad$ Empirical constant to evaluate tensile strength on single root

$\delta \quad$ Interface friction angle between soil and root $\left[{ }^{\circ}\right]$

$\phi^{\prime} \quad$ Soil shear strength angle $\left[{ }^{\circ}\right]$

$\theta^{*} \quad$ Inclination of the deformed root respect to the shear plane $\left[{ }^{\circ}\right]$

$\theta \quad$ Root orientation $\left[{ }^{\circ}\right]$

$\rho \quad$ Rate rooted area $\left(A_{\mathrm{R}}\right)$ and specimen area $\left(A_{\mathrm{p}}\right)$

$\sigma_{n}^{\prime} \quad$ Effective normal stress $\left[\mathrm{kN} / \mathrm{m}^{2}\right]$

$\sigma_{\mathrm{R}} \quad$ Root tensile stress $\left[\mathrm{kN} / \mathrm{m}^{2}\right]$

$\sigma_{\mathrm{VP}} \quad$ Vertical stress acting on the shear plane $\left[\mathrm{kN} / \mathrm{m}^{2}\right]$

$\tau_{\mathrm{P}} \quad$ Shear stress acting on the shear plane $\left[\mathrm{kN} / \mathrm{m}^{2}\right]$

$\psi \quad$ Shear distortion angle $\left[{ }^{\circ}\right]$

\section{Introduction}

Geosynthetic reinforced soil structures, since the early times, have always emphasized the environmental impact aspects. This also explains the fact that in Italy, the majority of geosynthetics reinforced soil structures consist of vegetated face steep slopes (Fig. 1).

The use of vegetation (grasses, shrubs, and trees) has also been recognized and incorporated in engineering practice from as early as the thirteenth and fourteenth centuries for erosion control and stabilization of shallow slope.

Starting from the 1960s, several researchers have investigated the role of the root system on soil reinforcement [1-17]. The purpose of this paper is to present the specific role of vegetation in soil reinforcement applications using a huge amount of both site and laboratory experimental data.

Seeding or live planting (e.g., live poles and brush layers) is the main method used to establish the vegetation on slopes. In particular, live planting method generally uses unrooted cuttings from live plants, installed vertically or in a direction perpendicular to the slope [18-20].

Scientific literature and field observations [21-24] show that removal of trees on natural slopes generally leads to an increase in slope failures. The short-term temporary 


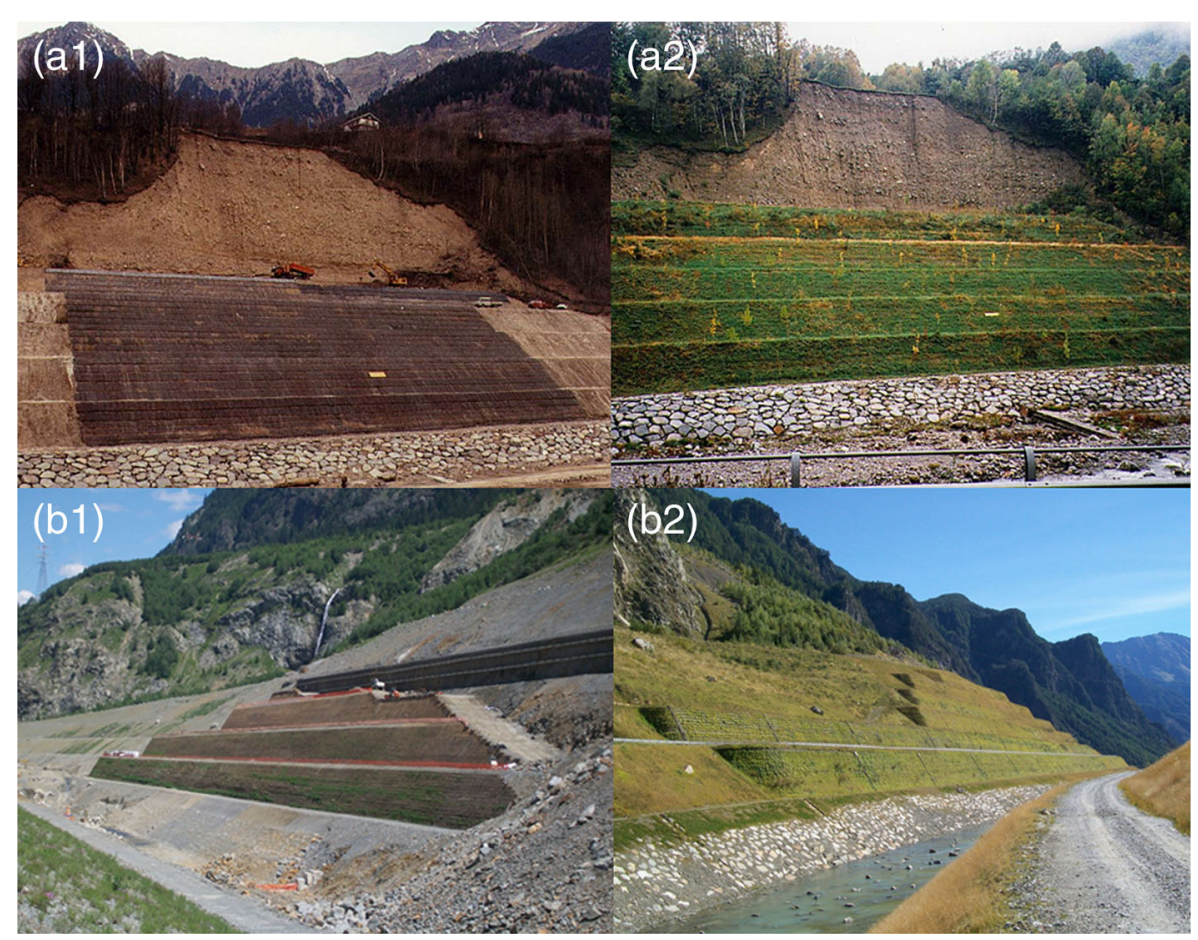

Fig. 1 Vegetated face steep slopes in landslide stabilization. a1, a2 Boscaccia (SO, Italy). b1, b2 Valpola (SO, Italy)

benefits (e.g., reduction of overload transferred to the ground, decrease in shear forces transmitted to the slope by wind action, reduction of the root wedging process) are overwhelmed by the decrease in slope stability due to the decay of roots which previously acted as reinforcements. In particular, the decay of roots may also cause the formation of void in the soil mass, which promotes erosion. Therefore, even if the weight of the trees increases the shear forces on the slopes, this effect is negligible compared to the increase in shear strength due to the presence of roots.

This particular effect is still investigated by different researchers all over the world.

Root reinforcement improves shallow slope stability by influencing both hydrological processes and geomechanical structure of the soil. In particular, considering the hydrological aspect, vegetation regulates infiltration of rainfall into the soil (retarding runoff velocity) and influences the transfer of water from soil to the atmosphere (reduction of soil moisture) by means of water absorption capacity, transpiration, and evaporation rates.

The rooted soil acts as a composite material in which the roots (with high tensile strength) embedded in the soil matrix (strong in compression and weak in tension) contribute to an increase in shear strength. A combined effect of soil and roots results in a reinforced soil.

Concerning the geomechanical aspect, the mechanical effects of the root system are linked to two main actions.

The first effect is due to the composite material when in shear loading condition; the shear stresses developed in the soil matrix are transferred to the root fibers through the 
tensile strength mobilized in the roots, increasing the rooted soil strength. The second effect involves roots intersecting the shear surfaces which act as individual anchors that pullout through the soil matrix without failure and mobilizes a soil-root interface friction force [8]. These geomechanical effects are generally considered in slope stability models with an increased soil cohesion term of the Mohr-Coulomb failure criterion.

For this reinforcing effect, in recent years, the use of vegetation in civil engineering and landscape works has grown in importance, but specific design standards are still under discussion for the use of vegetation for slope stabilization. According to this background, in order to select the most efficient species, literature has focused also on root system characteristics (root area ratio, root tensile strength, root-soil interaction) and on factors affecting root reinforcement.

The design and management of stabilization systems by plants require an accurate knowledge about the quantitative reinforcing root effects on soil strength. This objective can generally be achieved by means of (i) laboratory tensile tests on single roots with different diameters; (ii) laboratory direct shear tests on root-permeated soil specimens; (iii) in situ pullout tests on roots embedded in soil; and (iv) back analysis of collapsed slopes after storms.

\section{Factors Affecting Root Reinforcement of Soil}

The increase in soil strength by means of roots involves compound mechanisms due to multitude of interactions between roots and soil. Figure 2 schematizes the main factors affecting the root-soil system [25]. There are many factors that influence the magnitude of root reinforcement of soil, and the characterization of the system is quite complex.

Among all factors, the root distribution and the strength properties of the root are more important, and their influence depends on different aspects as follows: (i) genetic, biochemical, geometrical, and morphological characteristic of the root system, (ii)

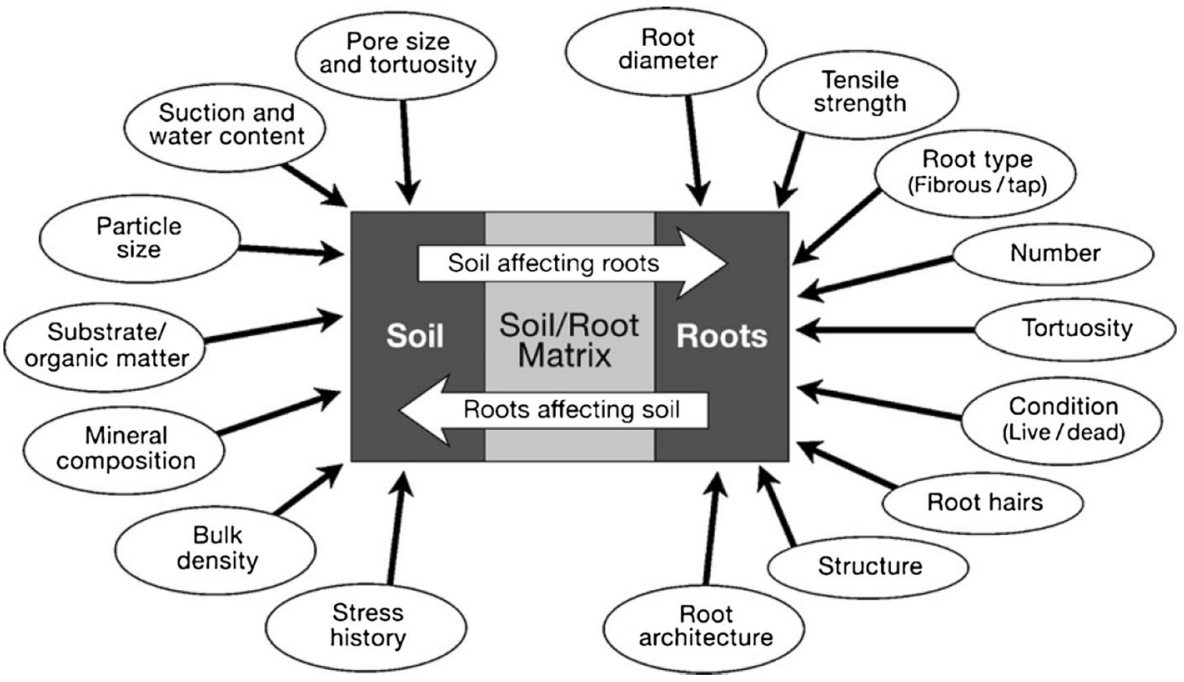

Fig. 2 Main factors affecting soil and root strength [25] 
mechanical characteristics (e.g., tensile strength and stiffness) of the root system, (iii) geotechnical and biochemical characteristic of the soil in contact, (iv) land use management, and (v) other environmental characteristics (e.g., interaction between different plants, climate characteristic, aeration, moisture, nutrient, organic matter content, growing location, fire events, age, and tree heath). Therefore, it is clear that a large heterogeneity in soil reinforced by means of root could occur considering different depths and locations.

In literature, the root reinforcement is expressed as an additional root cohesion term of the Mohr-Coulomb failure criterion [26, 15, 27, 6, 28] which can be simply incorporated into slope stability models [29].

$\mathrm{Wu}[30]$ proposed to estimate the root cohesion $(\Delta c)$ using the following model:

$$
\Delta c=K \cdot \sum_{i=1}^{N}\left[T_{R_{i}} \cdot \frac{A_{R_{i}}}{A}\right]
$$

where $K$ is a correction factor which takes in account the inclination of the roots crossing the shear plane; $T_{\mathrm{R}_{i}}$ is the average root tensile strength per average crosssectional area of diameter class $i$; $A_{\mathrm{R}_{i}}$ is cross-sectional area of the root diameter class $i$; and $A$ is the specimen area.

$A_{\mathrm{R}} / A$ is the root area ratio (RAR), and it provides a measure of root density within the soil. In particular, RAR is defined as the fraction of the soil cross-sectional area occupied by roots per unit area [11]. RAR varies greatly among species and different depths. Generally, RAR decreases with soil depth and with the distance from tree trunk $[26,12,31]$. Bischetti et al. [31] have reported that mainly RAR decreases with depth (with the exception, the first shallowest layer) because of a decrease of aeration, nutrients, and the presence of more compacted layers (Fig. 3).

In order to obtain the RAR value, two methods are usually adopted: core break sampling and counting root sampling. RAR estimation by using core break [32, 33] implies hypothesis about the spatial distribution of roots inside the sample. Counting root method sampling $[33,32,31]$ may use the image analysis technique $[34,35]$.

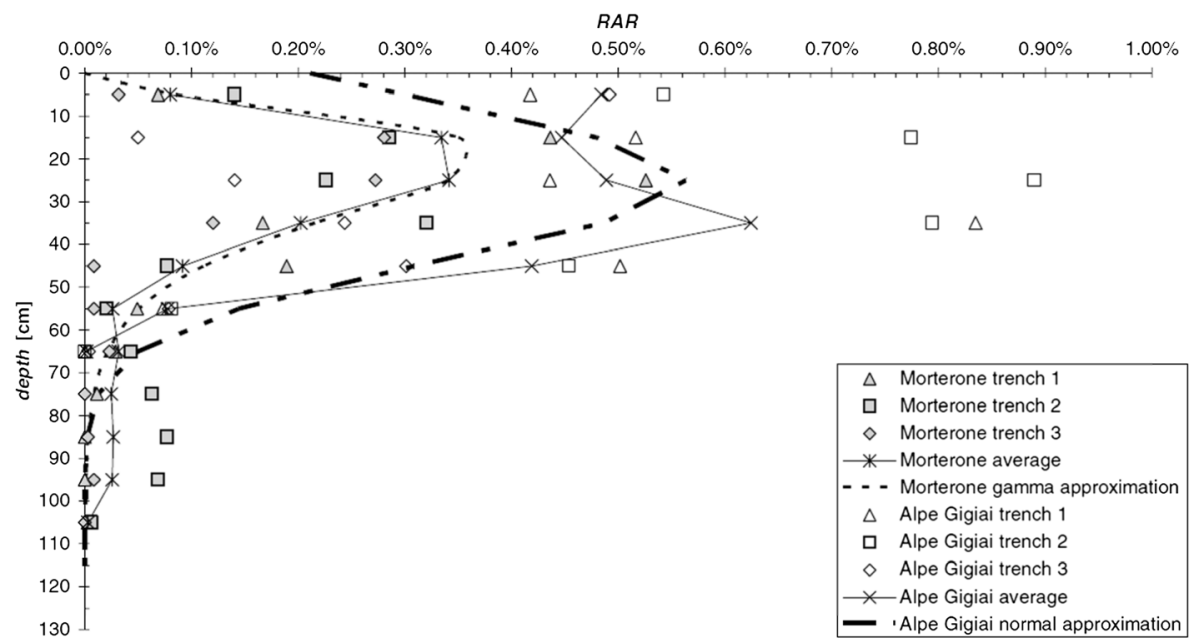

Fig. 3 RAR for beech at two study sites (values at each trench, average and analytical approximations) [31] 
The tensile strength of single roots of the vegetations (tree, shrubs, or grass) may be measured by carrying out tensile tests on root segments. Available data show that generally the strength varies between 5 and $60 \mathrm{MPa}$ [36] and also varies with diameter and location [24, 12, 19, 37].

However, the conceptual framework proposed by $\mathrm{Wu}[30]$ is based on the assumption of simultaneous failure in tension of all roots, but the phenomenon of the progressive breaking of roots has been demonstrated by means of pullout and direct shear test on branched roots $[38,39,17,40,41]$. Results that show how the activation of roots strength within a bundle is not synchronous. Therefore, root pullout resistance is mobilized gradually and roots fail in tension at different displacements, depending on their individual morphology. Moreover, the root-reinforcing mechanism contributes to overall shearing resistance through a 3-D soil-root interaction system [42]. These assumptions may significantly overestimate the role of root reinforcement of soils based on Wu's model [9, 13, 39, 43, 40, 44-46].

As previously mentioned, a further aspect to consider is the root distribution. Different researchers [19, 47-49, 42, 50] have studied the influence of the root architecture (i.e., concentration, branching characteristics, and spatial distribution of the root system in the soil) on the reinforcing mechanism due to the rooting system. It could highly influence the distribution of stresses within the soil and could affect the mechanical behavior (pullout resistance) of rooted soils.

Reubens et al. [47] summarized the root characteristics that could affect the behavior of the soil-root system. In particular, the authors identified the following factors: root density, root length density, number of roots, RAR, root taper, basal diameter, inclination, percentage of soil with fine roots, maximum root depth, branching pattern, angle between lateral roots, and total length after the intersection point.

On the basis of studies performed, Reubens et al. [47] stated that a dense rooting pattern of fine roots in the top layer in combination with coarse and deeply penetrating roots was most effective against shallow slope failure.

Yen [51] classified the structure of the roots according to five classes based on the branching pattern, namely VH-type, H-type, V-type, R-type, and M-type (Fig. 4). On the basis of analysis performed by Yen [51], the H-type and the VH-type have reported a better behavior in the field of slope stabilization and wind resistance.

Fan and Chen [42], based on in situ direct shear tests, showed that the V-type root architecture has an efficient branching pattern that improve soil shear strength.

Fan and Chen [42] proposed a procedure to measure the root structure. Root orientation has been defined as the angle opposite direction to the shear stresses (Fig. 5).

The authors quantify the root structure in terms of root orientation $(\theta)$, number of roots, and cross-sectional area of roots by projecting and mapping the root system on a vertical plane parallel to the shear direction. As shown in Fig. 6, the root orientations were divided into three groups. In the first group, useful to characterize lateral roots, the root orientations range from $10^{\circ}$ to the horizontal plane. In the second group, useful to characterize oblique roots, the root orientations range from $10^{\circ}$ to $70^{\circ}$. The root orientations of third group, useful to represent the growth direction of vertical roots, range from $20^{\circ}$ from the vertical. 


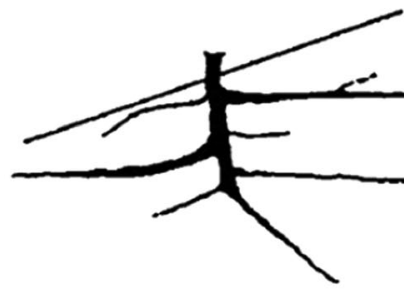

(a) H-type

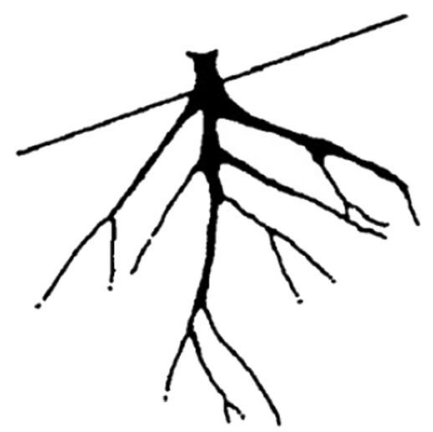

(b) R-type

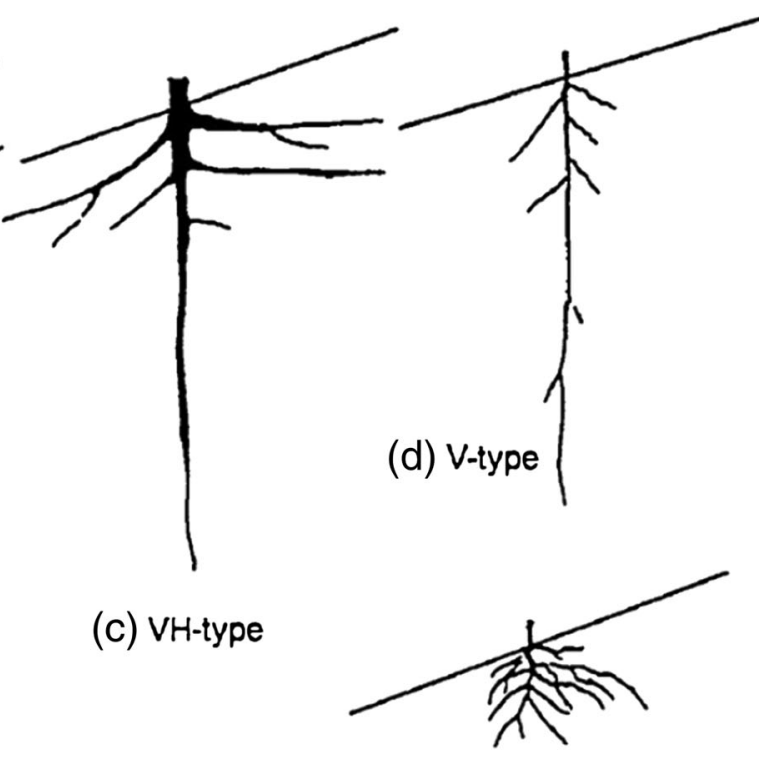

(e) M-type

Fig. 4 a-e Branching pattern proposed by Yen [51]

\section{Experimental Tests}

In order to evaluate the increase in soil shear strength due to root reinforcement, it is possible to study the soil-root system behavior by using in situ tests (e.g., direct shear tests and pullout tests) and laboratory tests (e.g., tensile tests and direct shear tests) or modelling the root-soil interaction.

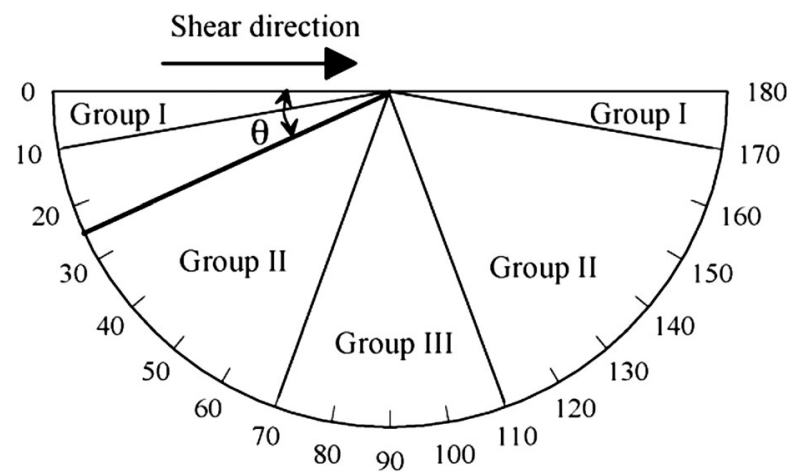

Root orientation, $\theta\left(^{\circ}\right)$

Fig. 5 Classification of root structure by using root orientation $\theta$ [42] 


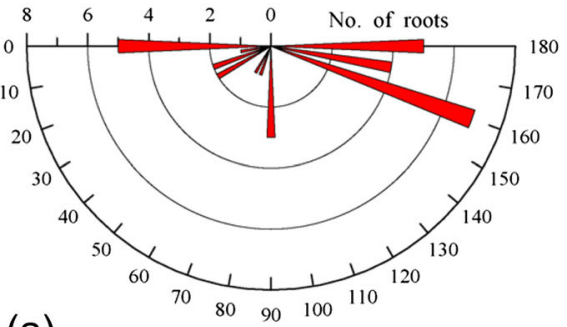

(a)

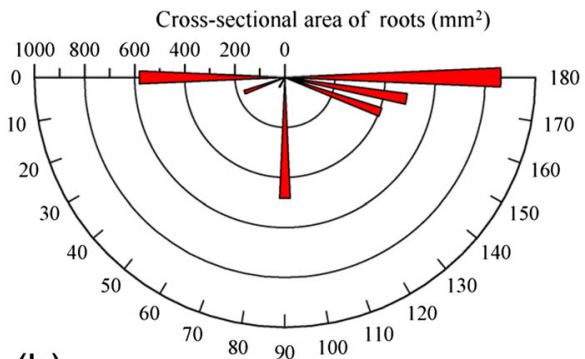

Root orientation, $\theta\left({ }^{\circ}\right)$

Fig. 6 Examples of typical distribution of root orientations vs. a number of roots and $\mathbf{b}$ cross-sectional area of roots (Japanese Mallotus plant species) [42]

\section{Laboratory Tensile Tests on Single Roots}

Root tensile strength represents an important index of soil reinforcement, and its evaluation through laboratory tests is affected by root diameter, root species, seasons, rate of displacement of test [14], living or decaying of roots [15, 52], and environmental conditions. Indeed, laboratory results show a great variability among different species and for the same species. Bischetti et al. [31] showed that, in general, the value of the standard deviation for the measured tensile strength is greater than the mean value (up to twice).

Live roots were usually collected from the site by using hand or hydraulic excavation methods taking care to avoid any root damage or stress. Cazzuffi and Tironi [37] showed how using a water jet pressure equal to 4 bars permits to remove progressively and smoothly the entire soil around the plants (Fig. 7).

All the specimens are generally placed in pierced plastic bags and then conditioned at $20{ }^{\circ} \mathrm{C}$ and $65 \%$ relative humidity to ensure the same degree of preservation of the biomechanical properties of the roots until the execution of the tensile tests.

Bischetti et al. [53] had conserved roots for few weeks with different techniques [54] verifying that results, in term of tensile strength, were not affected by the used conservation method.

The tensile test procedures usually adopted by different researchers are the following. In a computer-controlled electronic universal testing machine, the root samples are fastened to a clamping system developed to avoid root damage at clamping points;

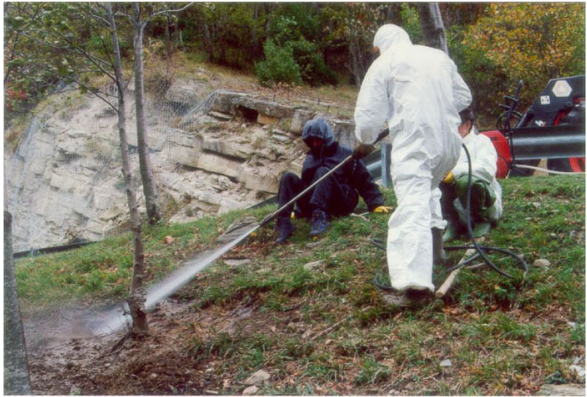

(a) Performing of the hydraulic excavation (pressure at about 4 bars)

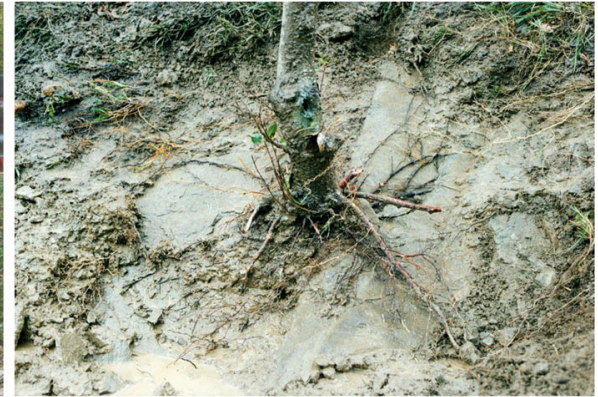

(b) Cordata alder roots exposed after final excavation by hands

Fig. 7 a, b Sampling procedure by using hydraulic excavation methods [37] 
then, a constant rate of displacement (generally varying from 2 to $20 \mathrm{~mm} / \mathrm{min}$ ) is applied. Test is valid when the root is broken in the middle of the specimen. Clamping is the most critical issue when measuring root strength (Fig. 8).

The root diameter $(d)$ is the most important factor affecting the laboratory tensile tests $\left(t_{\mathrm{R}}\right)$ on single roots, and Zhang et al. [55] proposed a procedure in order to reduce the overestimate of the tensile strength due to the measure of the actual diameter.

The tensile strength at rupture $(\mathrm{Pa})$ is calculated by the following expression:

$$
t_{\mathrm{R}}=\frac{T_{\mathrm{R}}}{A_{\mathrm{R}}}
$$

In which $A_{\mathrm{R}}$ is the cross-sectional area of the root that may be estimated as the average of root diameters.

The laboratory tensile tests $\left(t_{\mathrm{R}}\right)$ on single roots tend to decrease with increasing root diameter according to the following power function:

$$
t_{\mathrm{R}}=\alpha \cdot d^{-\beta}
$$

where $\alpha$ and $\beta$ are empirical constants.

Table 1 shows a database of values of $t_{\mathrm{R}}$ obtained by many researchers for different root species using data from the literature.

The $\alpha$ and $\beta$ coefficients of trees species seem to be significantly different compared to those obtained for grass/herb species but not compared to shrub species.

Cazzuffi and Tironi [37] showed that the experimental studies developed by Centro Elettrotecnico Sperimentale Italiano (CESI) SpA had focused on the evaluation of root tensile strength related to nine kinds of plants, commonly used for slope stabilization in

Fig. 8 Tensile testing device

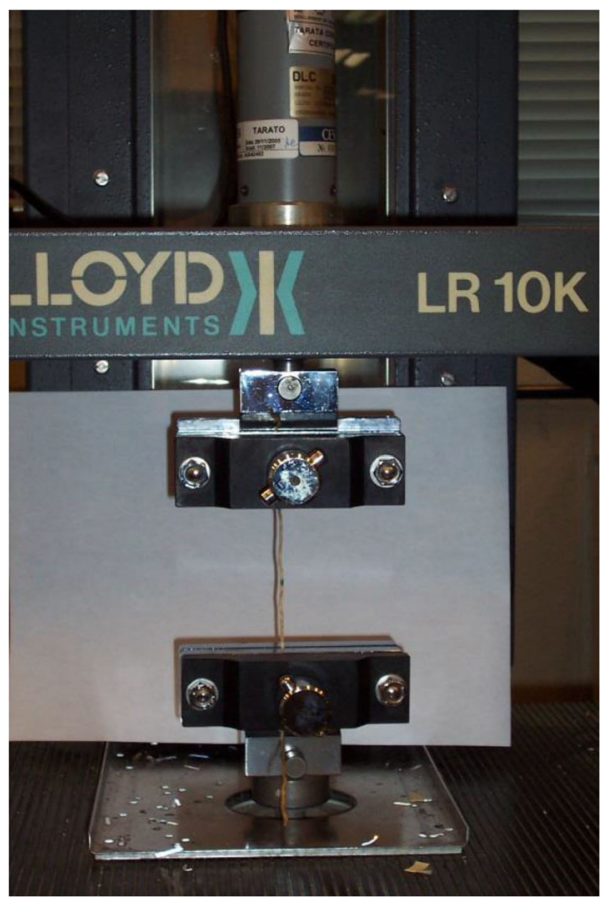


Table 1 Data collected from recent studies on the relationship between root tensile strength (tR) and diameter $d[31,56,42,55,57,43,58,50,59,25,49,26,60-64,40]$

\begin{tabular}{|c|c|c|c|c|c|c|}
\hline No. & Species & Functional group & $v[\mathrm{~mm} / \mathrm{min}]$ & $d[\mathrm{~mm}]$ & $\alpha$ & $\beta$ \\
\hline 1 & Alnus viridis & Tree & 10 & $0-5$ & 34.76 & 0.69 \\
\hline 2 & Salix caprea & Tree & 10 & $0-5$ & 34.50 & 1.02 \\
\hline 3 & Salix purpurea & Tree & 10 & $0-5$ & 26.33 & 0.95 \\
\hline 4 & Fagus selvatica & Tree & 10 & $0-5$ & 41.65 & 0.97 \\
\hline 5 & Corylus avellana & Tree & 10 & $0-5$ & 60.15 & 0.75 \\
\hline 6 & Fraxinus excelsior & Tree & 10 & $0-5$ & 35.73 & 1.11 \\
\hline 7 & Picea abies & Tree & 10 & $0-5$ & 28.10 & 0.72 \\
\hline 8 & Laris decidua & Tree & 10 & $0-5$ & 33.45 & 0.75 \\
\hline 9 & Lygeum spartum & Herb/grass & 10 & $0-5$ & 60.73 & 1.30 \\
\hline 10 & Atriplex halimus & Shrub & 10 & $0-5$ & 72.97 & 0.60 \\
\hline 11 & Pistacia lentiscus & Shrub & 10 & $0-5$ & 91.25 & 0.45 \\
\hline 12 & Hibiscus tiliaceus & Tree & 2 & $0-7$ & 106.90 & 1.20 \\
\hline 13 & Mallotus japonicus & Tree & 2 & $0-7$ & 23.61 & 0.41 \\
\hline 14 & Sapium sebiferum & Tree & 2 & $0-7$ & 41.17 & 0.89 \\
\hline 15 & Casuarina equisetifolia & Tree & 2 & $0-7$ & 43.90 & 0.53 \\
\hline 16 & Leucaena leucocephala & Tree & 2 & $0-7$ & 32.55 & 0.75 \\
\hline 17 & Pinus tabulaeformis & Tree & 10 & $0-8$ & 17.81 & 0.20 \\
\hline 18 & Alnus viridis & Tree & 20 & $0.5-5$ & 20.74 & 0.25 \\
\hline 19 & Salix & Tree & 21 & $0.5-6$ & 47.34 & 0.25 \\
\hline 20 & Alnus cordata & Tree & 20 & $0.7-4.3$ & 17.78 & 0.13 \\
\hline 21 & Quercus cerris & Tree & 20 & $0.7-4.3$ & 24.57 & 0.17 \\
\hline 22 & Sesbania cannabina & Shrub & 2 & $0.5-4.5$ & 60.48 & 0.86 \\
\hline 23 & Tamarix canariensis & Tree & 10 & $0.10-4.80$ & 31.74 & 0.89 \\
\hline 24 & Atriplex halimus & Shrub & 10 & $0.23-4.68$ & 45.59 & 0.56 \\
\hline 25 & Salsola genistoides & Shrub & 10 & $0.30-3.84$ & 44.23 & 0.51 \\
\hline 26 & Thymelaea hirsuta & Shrub & 10 & $0.18-2.70$ & 33.31 & 0.64 \\
\hline 27 & Artemisia barrelieri & Shrub & 10 & $0.16-2.15$ & 30.12 & 0.61 \\
\hline 28 & Fumana thymifolia & Shrub & 10 & $0.19-2.43$ & 15.71 & 0.66 \\
\hline 29 & Dorycnium pentaphyllum & Shrub & 10 & $0.27-4.35$ & 16.32 & 0.62 \\
\hline 30 & Teucrium capitatum & Shrub & 10 & $0.22-2.60$ & 18.72 & 0.45 \\
\hline 31 & Dittrichia viscosa & Shrub & 10 & $0.30-5.50$ & 18.94 & 0.45 \\
\hline 32 & Thymus zygis & Shrub & 10 & $0.12-2.88$ & 19.31 & 0.73 \\
\hline 33 & Rosmarinus officinalis & Shrub & 10 & $0.16-3.60$ & 12.89 & 0.77 \\
\hline 34 & Nerium oleander & Shrub & 10 & $0.09-4.11$ & 4.41 & 1.75 \\
\hline 35 & Limonium supinum & Herb/grass & 10 & $0.34-3.90$ & 33.82 & 0.85 \\
\hline 36 & Plantago albicans & Herb/grass & 10 & $0.21-2.55$ & 16.75 & 0.52 \\
\hline 37 & Brachypodium retusum & Herb/grass & 10 & $0.10-1.45$ & 45.05 & 0.61 \\
\hline 38 & Stipa tenacissima & Herb/grass & 10 & $0.43-1.34$ & 24.34 & 0.61 \\
\hline 39 & Lygeum spartum & Herb/grass & 10 & $0.26-2.72$ & 19.28 & 0.68 \\
\hline 40 & Helictotrichon filifolium & Herb/grass & 10 & $0.34-1.22$ & 14.51 & 1.08 \\
\hline 41 & Piptatherum miliaceum & Herb/grass & 10 & $0.10-0.64$ & 11.49 & 1.77 \\
\hline
\end{tabular}


Table 1 (continued)

\begin{tabular}{|c|c|c|c|c|c|c|}
\hline No. & Species & Functional group & $v[\mathrm{~mm} / \mathrm{min}]$ & $d[\mathrm{~mm}]$ & $\alpha$ & $\beta$ \\
\hline 42 & Avenula bromoides & Herb/grass & 10 & $0.15-0.32$ & 4.77 & 1.52 \\
\hline 43 & Phragmites australis & Herb/grass & 10 & $0.10-7.91$ & 34.29 & 0.78 \\
\hline 44 & Juncus acutus & Herb/grass & 10 & $0.18-1.10$ & 23.23 & 0.89 \\
\hline 45 & S-Elygrass & Herb/grass & 20 & $0.51-1.07$ & 180.65 & 1.87 \\
\hline 46 & S-Eragrass & Herb/grass & 20 & $0.24-1.08$ & 62.16 & 0.44 \\
\hline 47 & S-Pangrass & Herb/grass & 20 & $0.76-1.91$ & 29.37 & 0.33 \\
\hline 48 & S-Vetiver & Herb/grass & 20 & $0.73-1.6$ & 131.08 & 1.08 \\
\hline 49 & P-Cold Vetiver & Herb/grass & 20 & $0.56-1.9$ & 35.53 & 1.00 \\
\hline 50 & P-Elygrass & Herb/grass & 20 & $0.4-1.2$ & 154.45 & 1.90 \\
\hline 51 & P-Eragrass & Herb/grass & 20 & $0.4-0.84$ & 25.87 & 3.75 \\
\hline 52 & P-Pangrass & Herb/grass & 20 & $0.58-1.85$ & 45.14 & 0.73 \\
\hline 53 & P-Vetiver & Herb/grass & 20 & $0.48-1.46$ & 66.24 & 1.18 \\
\hline 54 & Lotus corniculatus & Herb/grass & 10 & $0.35-1.3$ & 3.52 & 1.41 \\
\hline 55 & Trifolium pratese & Herb/grass & 10 & $0.3-1.65$ & 12.52 & 0.75 \\
\hline 56 & Medicago sativa & Herb/grass & 10 & $0.1-1.15$ & 10.57 & 1.54 \\
\hline 57 & Festuca pratensis & Herb/grass & 10 & $0.1-0.65$ & 2.58 & 2.01 \\
\hline 58 & Lolium perenne & Herb/grass & 10 & $0.1-0.7$ & 1.93 & 2.10 \\
\hline 59 & Panacum virgatum & Herb/grass & - & $0-3$ & 35.20 & 1.78 \\
\hline 60 & Phalaris arundinacea & Herb/grass & - & $0-3$ & 1.70 & 1.71 \\
\hline 61 & Lolium perenne & Herb/grass & - & $0-3$ & 2.10 & 1.65 \\
\hline 62 & Wet meadow & Herb/grass & - & $0-3$ & 20.90 & 1.21 \\
\hline 63 & Salix nigra & Tree & - & $0-10$ & 45.90 & 1.10 \\
\hline 64 & Liquidamber styraciflua & Tree & - & $0-10$ & 52.10 & 1.04 \\
\hline 65 & Tripsacum dactyloides & Herb/grass & - & $0-3$ & 43.10 & 1.00 \\
\hline 66 & Elaeagnus angustifolia & Tree & - & $0-10$ & 22.10 & 1.00 \\
\hline 67 & Dry meadow & Herb/grass & - & $0-3$ & 22.10 & 0.99 \\
\hline 68 & Pinus palustris & Tree & - & $0-10$ & 30.00 & 0.99 \\
\hline 69 & Plantanus occidentalis & tree & - & $0-10$ & 50.50 & 0.94 \\
\hline 70 & Tamarix ramosissima & Shrub & - & $0-3$ & 23.60 & 0.90 \\
\hline 71 & Salix lemmonii & Tree & - & $0-10$ & 25.90 & 0.86 \\
\hline 72 & Alnus tenuifolia & Tree & - & $0-10$ & 21.60 & 0.80 \\
\hline 73 & Rubus armeniacus & Shrub & - & $0-3$ & 19.50 & 0.69 \\
\hline 74 & Salix interior & Tree & - & $0-10$ & 25.20 & 0.68 \\
\hline 75 & Betula nigra & Tree & - & $0-10$ & 45.80 & 0.66 \\
\hline 76 & Pinus contorta & Tree & - & $0-10$ & 19.10 & 0.65 \\
\hline 77 & Populus spp. & Tree & - & $0-10$ & 18.90 & 0.64 \\
\hline 78 & Spiraea douglasii & Shrub & - & $0-3$ & 22.90 & 0.54 \\
\hline 79 & Salix geyeriana & Tree & - & $0-10$ & 23.30 & 0.51 \\
\hline 80 & Fraxinus latifolia & Tree & - & $0-10$ & 24.30 & 0.50 \\
\hline 81 & Betula laminifera & Tree & 10 & $0-10$ & 79.40 & 0.63 \\
\hline 82 & Aralia elata & Tree & 10 & $0-10$ & 93.08 & 0.76 \\
\hline 83 & Idesia polycarpa & Tree & 10 & $0-10$ & 14.34 & 1.32 \\
\hline
\end{tabular}


Table 1 (continued)

\begin{tabular}{|c|c|c|c|c|c|c|}
\hline No. & Species & Functional group & $v[\mathrm{~mm} / \mathrm{min}]$ & $d[\mathrm{~mm}]$ & $\alpha$ & $\beta$ \\
\hline 84 & Litsea cubeba & Tree & 10 & $0-10$ & 64.36 & 0.65 \\
\hline 85 & Carya cathayensis & Tree & 10 & $0-10$ & 74.28 & 0.65 \\
\hline 86 & Phyllostachys nidularia & Herb/grass & 10 & $0-10$ & 32.42 & 0.52 \\
\hline 87 & Pinus nigra & Tree & 2 & $0-7$ & 18.40 & 0.52 \\
\hline 88 & Pinus pinaster & Tree & 2 & $0-7$ & 23.40 & 0.87 \\
\hline 89 & Picea abies & Tree & 2 & $0-7$ & 37.86 & 0.51 \\
\hline 90 & Fagus sylvatica & Tree & 2 & $0-7$ & 63.51 & 0.61 \\
\hline 91 & Castanea sativa & Tree & 2 & $0-7$ & 31.92 & 0.73 \\
\hline 92 & Cryptomeria japonica 9 weeks & Tree & 10 & $0-4.5$ & 21.59 & 0.34 \\
\hline 93 & Cryptomeria japonica 20 weeks & Tree & 10 & $0-4.5$ & 25.79 & 0.37 \\
\hline 94 & Cryptomeria japonica 230 weeks & Tree & 10 & $0-4.5$ & 31.90 & 0.41 \\
\hline 95 & Hordeum vulgare & Herb/grass & 1 & $0-0.8$ & 2.63 & 1.62 \\
\hline 96 & Hordeum vulgare & Herb/grass & 1 & $0-1.6$ & 3.03 & 1.20 \\
\hline 97 & Hordeum vulgare & Herb/grass & 1 & $0-0.9$ & 2.04 & 1.27 \\
\hline 98 & Fagus sylvatica & Tree & 10 & $0-6$ & 41.57 & 0.98 \\
\hline 99 & Castanea sativa & Tree & 10 & $0-6$ & 17.86 & 0.53 \\
\hline 100 & Ostrya carpinifolia & Tree & 10 & $0-6$ & 21.89 & 0.43 \\
\hline 101 & Picea abies & Tree & 10 & $0-6$ & 28.10 & 0.72 \\
\hline 102 & Larix decidua & Tree & 10 & $0-6$ & 33.45 & 0.75 \\
\hline 103 & $\begin{array}{l}\text { Melaleuca ericifolia and } \\
\text { Eucalyptus camaldulensis }\end{array}$ & Tree & 2.5 & $0-18$ & 49.39 & 0.77 \\
\hline 104 & Liquidamber styraciflua & Tree & - & & 23.58 & 0.57 \\
\hline 105 & Carpinus betulus & Tree & 10 & $0-4.5$ & 34.24 & 0.45 \\
\hline 106 & Parrotia persica & Tree & 10 & $0-5$ & 33.05 & 0.37 \\
\hline 107 & Parrotia persica & Tree & 10 & $0-5$ & 26.84 & 0.37 \\
\hline 108 & Pinus contorta & Tree & - & $0-6$ & 31.40 & 1.28 \\
\hline 109 & Salix lemmonii & Tree & - & $0-9$ & 28.90 & 0.97 \\
\hline 110 & Casuarina glauca & Tree & 2 & $0-15$ & 29.67 & 0.41 \\
\hline 111 & Eucalyptus amplifolia & Tree & 2 & $0-15$ & 38.95 & 0.43 \\
\hline 112 & Eucalytpus elata & Tree & 2 & $0-15$ & 36.96 & 0.41 \\
\hline 113 & Acacia floribunda & Tree & 2 & $0-15$ & 74.36 & 0.48 \\
\hline
\end{tabular}

$t_{R}=\alpha \cdot \mathrm{d}^{-\beta}, t_{\mathrm{R}}[\mathrm{MPa}], d[\mathrm{~mm}]$

1-8 Bischetti et al. [31]; 9-11 Mattia et al. [56]; 12-16 Fan and Chen [42]; 17 Zhang et al. [54]; 18-21 Cazzuffi and Crippa [57]; 22 Fan and Chen [44]; 23-44 De Baets et al. [43]; 45-53 Cazzuffi and Crippa [57]; 54-58 Comino et al. [58]; 59-80 Thomas and Pollen-Bankhead [50]; 81-94 Genet et al. [59]; 95-97 Loades et al. [25]; 98-102 Bischetti et al. [49]; 103 Abernethy and Rutherfurd [26]; 104 Easson and Yarbrough [60]; 105 Abdi et al. [62]; 106 Abdi et al. [62]; 107 Abdi et al. [61]; 108-109 Simon et al. [64]; 110-113 Docker and Hubble [40]

different Italian regions. In particular, the authors tested the roots of the following species: (i) green alder and (ii) willow tree roots (typical of the Alpine regions), (iii) "cordata" alder, and (iv) turkey oak roots (typical of the Apennines regions) and five 


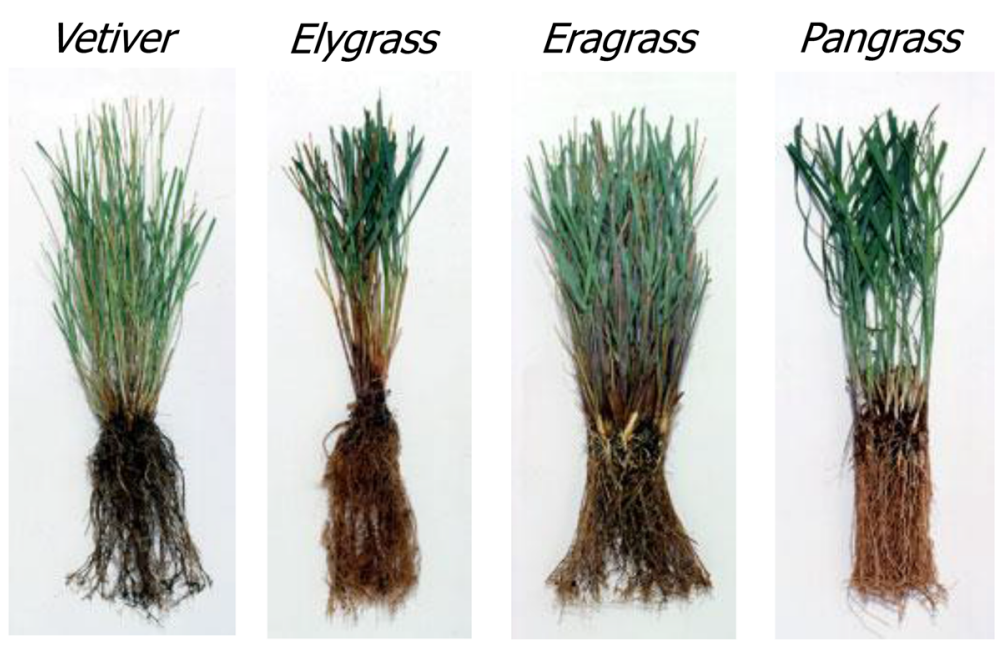

Fig. 9 Herb/grass species tested by Cazzuffi and Tironi [37]

kinds of perennial "Gramineae" plants imported from abroad. Concerning imported herb/grass species, the authors carried out tensile tests on (v) Eragrass, (vi) Elygrass, (vii) Cold Vetiver, (viii) Vetiver, and (ix) Pangrass (Fig. 9).

The researchers found that plants grown in pots generally were characterized by lower strength compared to the same plants grown on site (Fig. 10).

Figure 11 shows the results of tensile tests performed by Cazzuffi and Tironi [37] on tree species commonly used in Italian regions.

Generally, the correlation between tensile strength and root diameter is associated with chemical composition [65]. Many authors [66-68, 55] studied the influence of cellulose content on tensile strength behavior of roots. In particular, cellulose is the

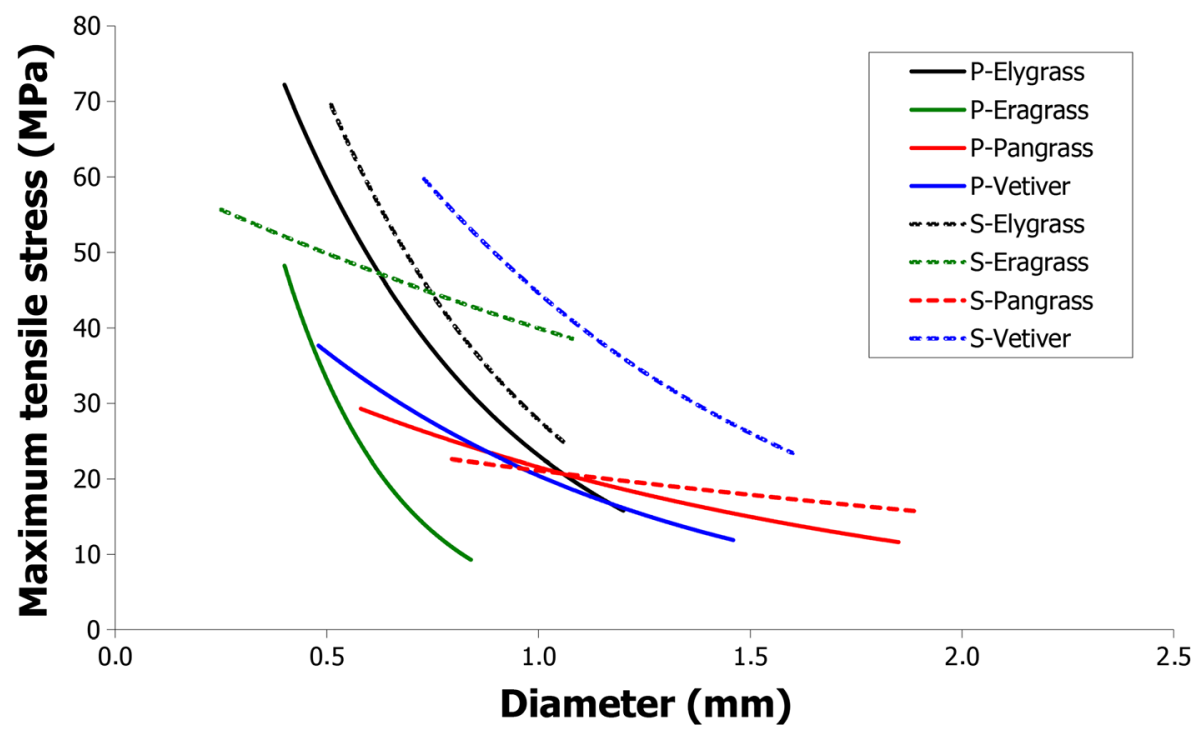

Fig. 10 Tensile tests results of herb/grass species grown both in natural conditions and in pots [37] 


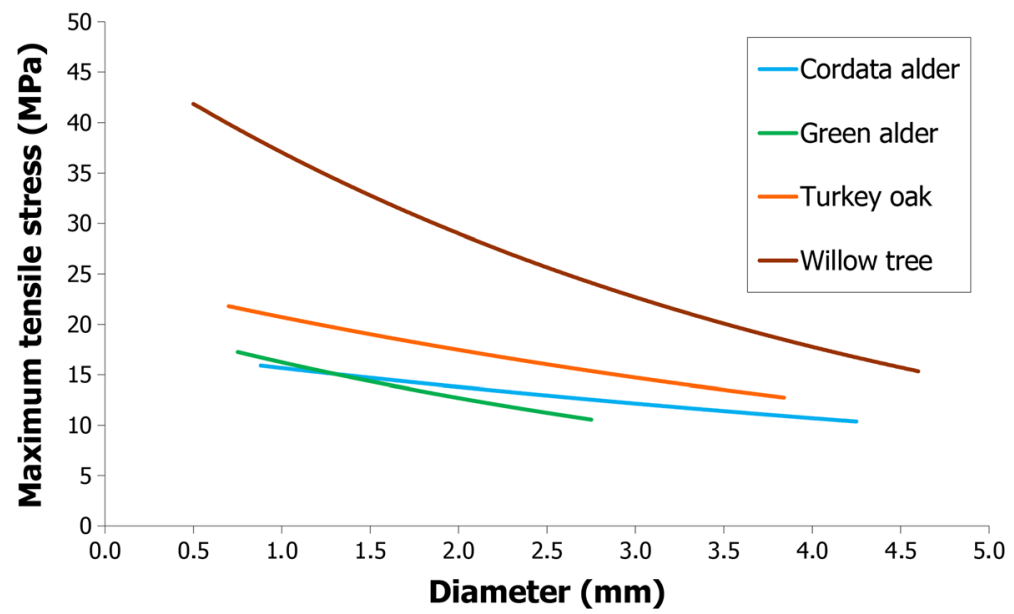

Fig. 11 Results of tensile tests performed on tree species commonly used in Italian regions [37]

most abundant polysaccharide in plant cells and consists of a linear unbranched polymer of glucose monomers, which generally has a flat, ribbon-like structure [69].

Genet et al. [68] showed how the cellulose content and tensile strength of roots could be significantly correlated. The authors found that the cellulose content decreases with the increase in diameter of the tested root. Moreover, cellulose content decreases with the decrease of measured tensile strength (Fig. 12).

Hathaway and Penny [65] studied the important effect of lignin content on strength properties. Lignin is one of the most abundant organic polymers in cell, exceeded only by cellulose, and provides the structural integrity of cell walls, which is crucial for woody plants with a high requirement for structural support and stem rigidity [70].

Zhang et al. [55] measured lignin, cellulose, and alpha-cellulose content of different species. The authors by correlating these results with the corresponding tensile strength

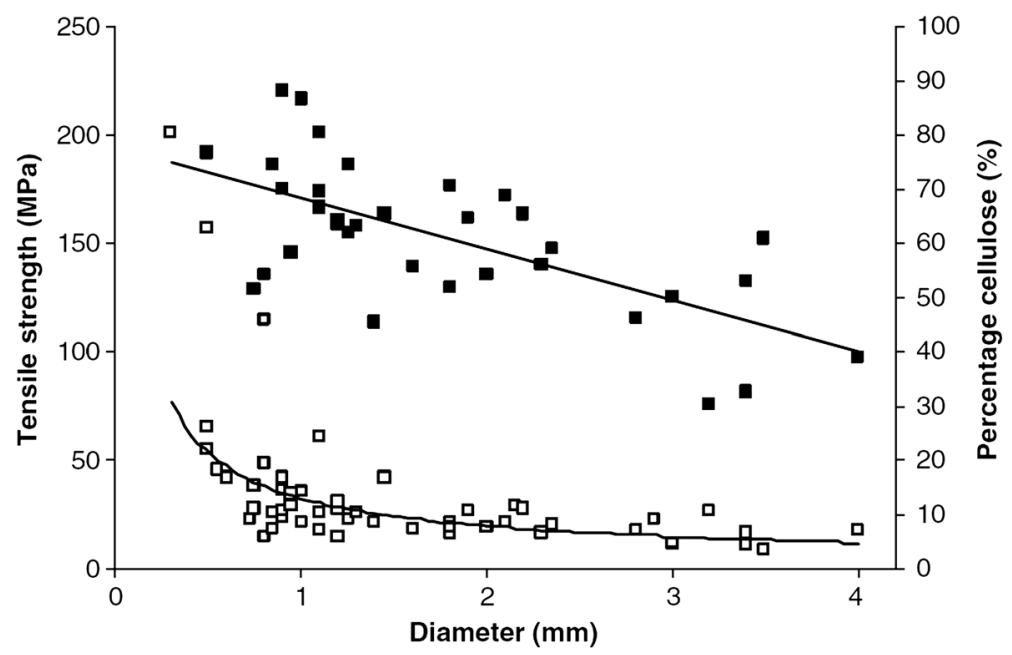

Fig. 12 Tensile strength (white squares) and cellulose content (black squares) vs. root diameter in roots of sweet chestnut [68] 
results showed that (i) the lignin content increase with the increasing in tensile strength and (ii) the cellulose contents decrease with the increasing of the tensile strength (in contrast to the results reported by Genet et al. [68]). Also, the ratios lignin/cellulose and lignin/alpha-cellulose decrease with the increasing of the diameter (Fig. 13) and therefore have a positive relationship with tensile strength. These results showed that lignin has a positive relationship with tensile strength and may be the load-bearing key element of the matrix.

Due to the chemical properties of the constituent material, the roots have a viscouselastoplastic behavior when subjected to tensile load. Due to the viscous behavior, the mechanical properties depend on test temperature and test rate. Cofie and Koolen [14] showed that the tensile strength increases with an increasing elongation rate. In order to determine an appropriate test rate, may be evaluated by the speed of the mass movement when the landslide occurs, but these velocities can be extremely variable [43].

Finally, tensile tests carried out on living and decaying roots [24, 15, 52] established that decomposition involves a decrease in mechanical resistance.

\section{Direct Shear Tests}

Only few references were found in the literature concerning shear strength evaluation of rooted soil in laboratory $[71,13,72-75]$ and on site $[7,40]$.

In order to quantify the contribution of roots to soil mechanical properties, Cazzuffi et al. [72] carried out laboratory direct shear test on undisturbed samples containing only soil and soil with roots. To achieve this objective, the authors carried out direct shear tests on undisturbed large dimension samples of soil and of rooted soil, directly collected from a site located in Southern Italy at different soil depths (i.e., 0.2, 0.4, and $0.6 \mathrm{~m}$ ).

Cazzuffi et al. [72] performed direct shear tests on plant roots of four different species of perennial "Gramineae" deep root plants (i.e., Eragrass, Elygrass, Pangrass,

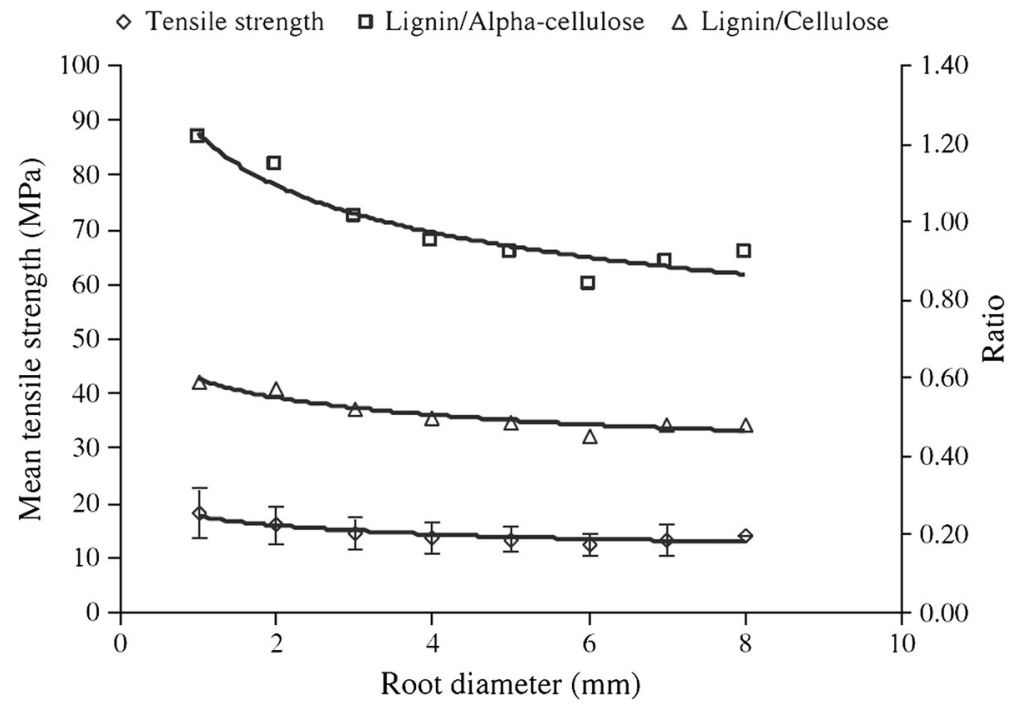

Fig. 13 Mean tensile strength (and ratios of lignin/cellulose and lignin/alpha-cellulose) vs. root diameter [55] 
and Vetiver). The soil constituting the slopes on which the perennial "Gramineae" were planted comprised of silt $(63.30 \%)$ and clay $(28.70 \%)$.

Different sample collection techniques were considered, taking into account the difficulties to extract samples of such dimensions and weights and the necessity to cause the minimum possible disturbance to the samples themselves. In order to minimize the sample disturbance, the authors chose the direct push sampling methods, which consists of pushing in a cylindrical sampler at the desired depth by an adequate equipment and then recovering the sampler, containing the undisturbed soil.

The extraction of the undisturbed samples was realized at the period coincident with the vegetative awakening of the planted "Gramineae" species. The collected undisturbed samples were sealed by wax to maintain constant moisture content.

Direct shear tests were carried out in a large direct shear device, on large cylindrical samples (i.e., $200 \mathrm{~mm}$ in diameter), in order to allow the complete development of the root resistance mechanism and to avoid scale effects. In order to perform tests on the soil column about $1 \mathrm{~m}$ high, it was necessary to realize a particular steel support, able to sustain and fix the sample during the test, in such a way that it would not bend (Fig. 14).

Direct shear tests were executed to a maximum displacement of $33 \mathrm{~mm}$, which represents the limit of the apparatus, imposing a constant shear displacement ratio of $0.2 \mathrm{~mm} / \mathrm{min}$, allowing to complete mobilize root contribution to shear strength. After shearing, the moisture content of the sample was measured and values between 25 and $47 \%$ were registered.

Figures 15, 16, and 17 show the shear stress-shear displacement curves for tests on soil with and without roots for different shear plane depths $(0.2,0.4$, and $0.6 \mathrm{~m})$.

Figure 18 shows normal stress (weight of the soil) vs. maximum shear stress for all direct shear tests carried out by Cazzuffi et al. [72]. The contribution of roots to soil shear strength is evident: in fact, in each test, the shear strength values of soil samples with roots are always higher than the values obtained from tests performed on soil samples without roots. Soil improved by using root reinforcement involves only an increase in cohesion, while the angle of friction of both the reinforced and unreinforced soils does not change.

It is interesting to compare these results with the tensile test ones results on the same type of gramineous plants [37]. It is noticed that the magnitude of tensile strength is proportionately linked to the value obtained on the same root reinforcement specie by direct shear tests. Elygrass and Vetiver, which are characterized by the highest root tensile strengths, are the species that were able to contribute the highest increase in soil
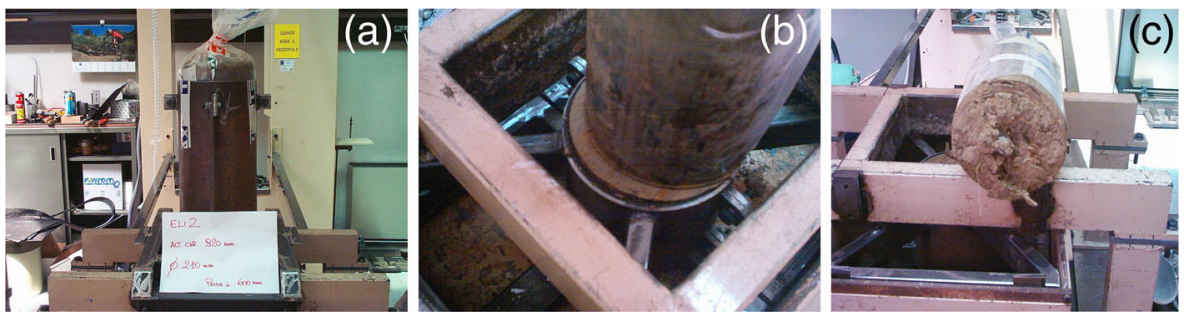

Fig. 14 Direct shear test device. a Positioning of the rooted soil sample inside the steel support. b Direct shear test carried out on the rooted specimen. c Specimen of rooted soil at the end of a direct shear test [57] 


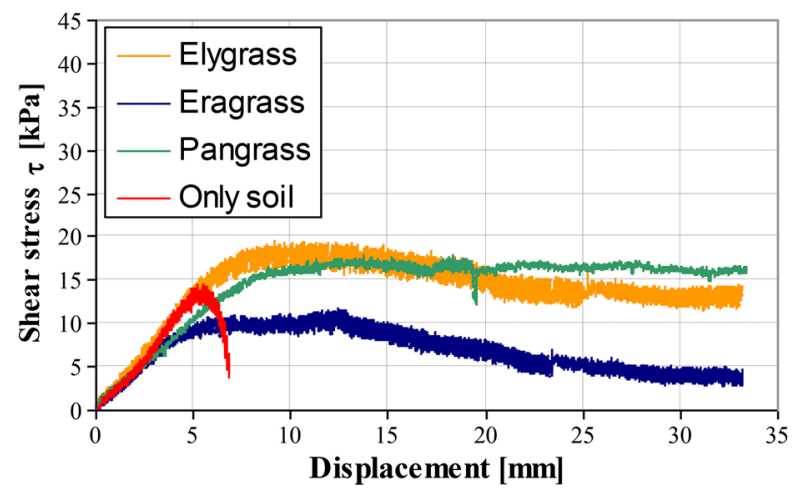

Fig. 15 Shear stress-shear displacement curves for soil samples with and without roots with shear plane depth of $0.2 \mathrm{~m} \mathrm{[57]}$

shear strength. On the other hand, the lowest shear strengths corresponded to the soil samples containing Eragrass and Pangrass root systems. Also, in this case, the variability related to tensile strength intervals should be considered.

$\mathrm{Hu}$ et al. [73] performed direct shear laboratory tests on both root-soil composite systems and only on the soil. The reinforced specimens were prepared mixing the soil (with a moisture content of $12.8 \%$ ) with shrub roots after 2 years of growth (fives species were studied). In order to replicate the characteristics of the actual shrub root of the hillslope, for the specimens' preparation (inner diameter of $6.18 \mathrm{~cm}$ and height of $2.0 \mathrm{~cm}$ ), roots characterized by were used: (i) diameter of $0.2-1.2 \mathrm{~mm}$, (ii) length equal to $40 \mathrm{~mm}$, and (iii) weight equal to $1.2 \mathrm{~g}$. The soil was then compacted at the same density as measured in situ (i.e., $1.58 \mathrm{~g} / \mathrm{cm}^{3}$ ). A vertical load was applied to the specimen, and the test was carried out at a constant rate of displacement $(2.4 \mathrm{~mm} /$ min) until shear failure occurred.

Test results show that the shear strength of the root-soil composite system increases linearly with the increasing of the vertical pressure (correlation greater than 0.99). In this experimental research, the reinforcing effect provided by roots adds only an increment of cohesion. The cohesion of the root-soil composite system was particularly greater than that of the soil alone (i.e., about $72 \%$ for the Atriplex canescens). The results show an increase in terms of shear strength due to root reinforcement of

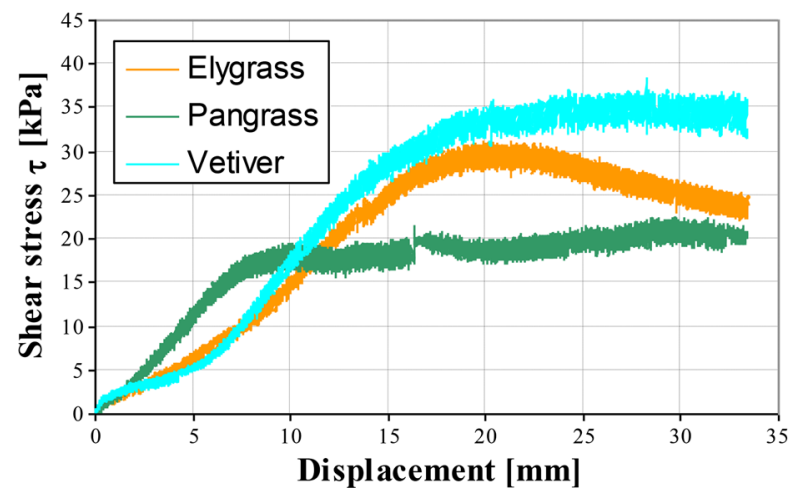

Fig. 16 Shear stress-shear displacement curves for rooted soil samples with shear plane depth of $0.4 \mathrm{~m}$ [57] 


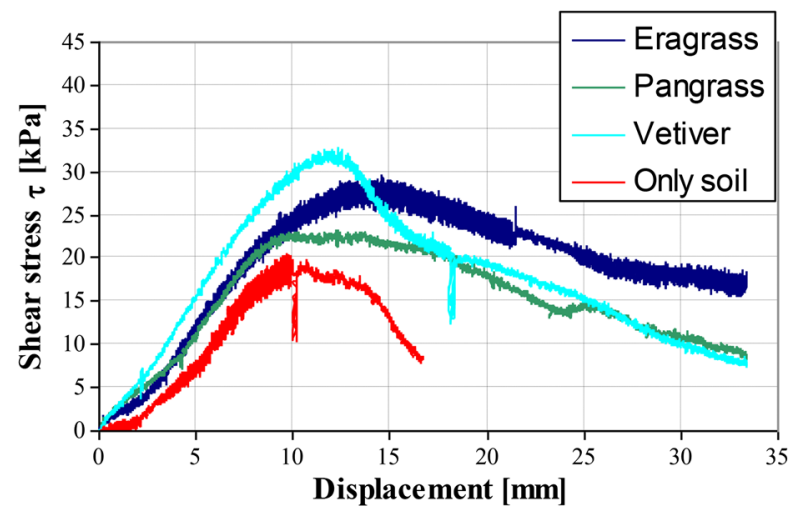

Fig. 17 Shear stress-displacement curves for soil samples with and without roots with shear plane depth of $0.6 \mathrm{~m} \mathrm{[57]}$

approximately $25 \%$ (for the $A$. canescens) compared with the shear strength of soil without roots.

Docker and Hubble [40] carried out direct in situ shear test on blocks of soil containing the roots of young trees of four different species (i.e., Casuarina glauca, Eucalyptus amplifolia, Eucalyptus elata, and Acacia floribunda).

Figure 19 shows the test procedure. First of all, the above-ground portion of the tree was removed, and a soil block (from $0.4 \times 0.4$ to $0.5 \times 0.5 \mathrm{~m}$ at the base and from 0.21 to $0.44 \mathrm{~m}$ in height) was separated from greater soil mass by means of trenches. Then, the rooted soil was saturated for $24 \mathrm{~h}$, but before starting of shear test, the block was in a partially saturated state. In order to simulate different soil shear depths, sets of weights from 0 to $470 \mathrm{~kg}$ were placed on the top of the block. The shear apparatus, placed in the trench between the soil block and the soil mass, consisted of two plates and two hydraulic hand pumps cylinders of $5 \mathrm{t}$ capacity to provide the shearing force. The shear force was applied at a constant rate of displacement (i.e., $1.5 \mathrm{~mm} / \mathrm{min}$ ). At the end

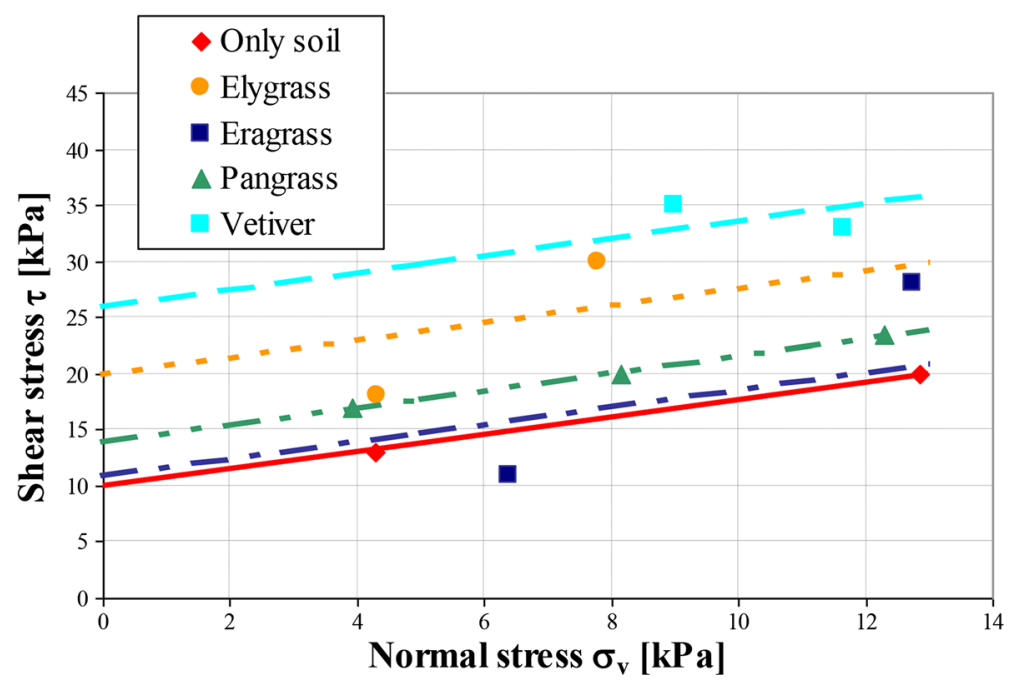

Fig. 18 Maximum shear stresses vs. normal stress registered in direct shear tests [57] 


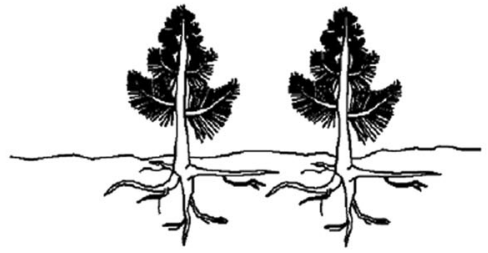

1. Trees grown in plantation for between 16 and 27 months

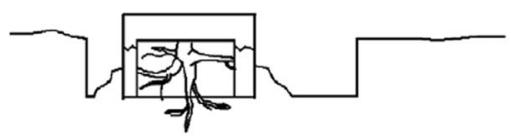

3. Soil block saturated up to 24 hours prior to testing

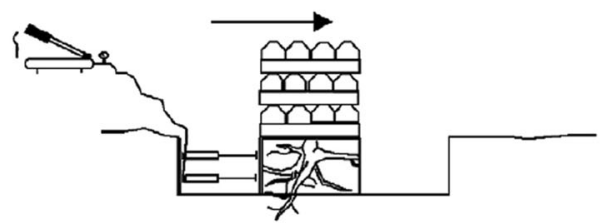

5. Hydraulic pressure applied by hand pump to push soil block along pre-determined failure plane

Fig. 19 In situ shear test method [40]

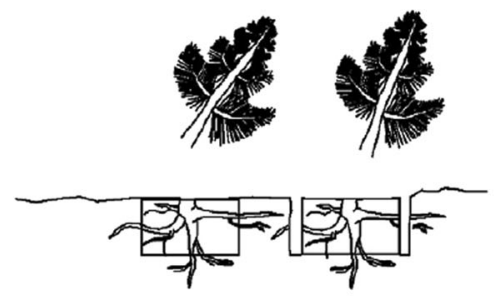

2. Above-ground tree removed and soil blocks cut from greater soil mass

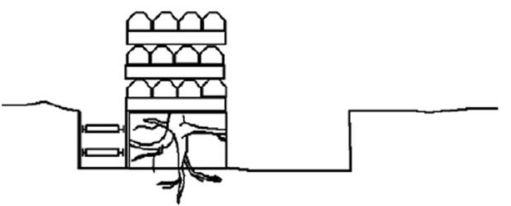

4. Hydraulic apparatus lowered into tranch and normal load applied to the block

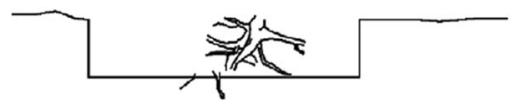

6. At the completion of testing soil is removed from around the roots and the diamters of all roots crossing the shear plane are recorded

of the test, the block was broken to reveal and to measure the roots present at the shear plane. The increase in term of shear resistance was determined by measuring the difference between the peak shear stress obtained on rooted soil block and the peak shear stress for soil-only block at the same normal vertical stress.

In general, in situ direct shear results showed softening behavior, and the loss of shear strength generally decrease with the increasing of the applied normal loads.

Figure 20a shows the maximum shear strength vs. normal stress, and values of rooted soil are greater than values of unreinforced soil.

Moreover, the authors calculated a relative increase in shear stress comparing the difference between the maximum shear stress for the root reinforced test and the MohrCoulomb failure envelope for the soil at the same normal pressure. The resulting shear stress increase was plotted against RAR calculated at the shear surface. For all the studied species, a linear relationship between the increased shear stress and RAR was observed, so a greater density of roots in the shear plane leads to a greater increased shear resistance of the soil (Fig. 20b).

In situ direct shear tests performed by Fan and Chen [42] allowed to correlate the shear strength increment $(\Delta c)$ provided by roots and the tensile force of roots per unit area of the soil $\left(t_{\mathrm{R}}\right)$ for each of the tested plant species. The $t_{\mathrm{R}}$ value both on roots 
(a)

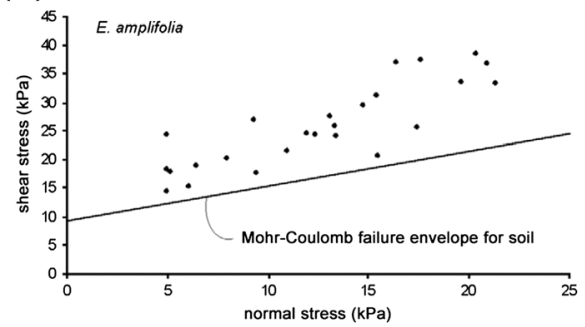

(b)

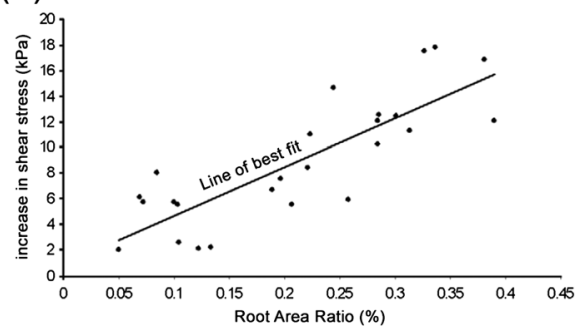

Fig. 20 Typical in situ shear test results for Eucalyptus amplifolia carried out by Docker and Hubber [40]. a Shear stress vs. normal stress and $\mathbf{b}$ increase in shear stress vs. RAR

crossing the shear plane and on all roots in a single plant was calculated in order to investigate the efficiency of the entire root architecture in providing the shear strength increment. Figure 21 shows the shear strength increments plotted against the tensile force of roots per unit area of the soil for one of the studied species. The correlations between $\Delta c$ and $t_{\mathrm{R}}$ for each of the plant species show approximately a linear relationship. When the tensile force of roots per unit area of the soil $\left(t_{R}\right)$ was calculated based on roots crossing the shear plane, the ratios between $\Delta c$ and $t_{\mathrm{R}}$ range from 0.30 to 0.87 for the tested plant species. When $t_{\mathrm{R}}$ was calculated based on all roots in a single plant, the ratios range from 0.11 to 0.49 .

\section{Pullout In Situ Tests}

The ultimate mobilized root strength depends on the roots' failure mode (i.e., pullout or tensile strength failure) of the root-reinforced soil.

$\mathrm{Wu}[36]$ underlined the difference between the tensile strength of a root segment or strength at failure generally measured by means of in situ pullout tests. When a tensile force is applied to a non-confined edge portion of the root embedded in the soil mass, failure could occur by the tensile failure in the main root, the progressive failure in the
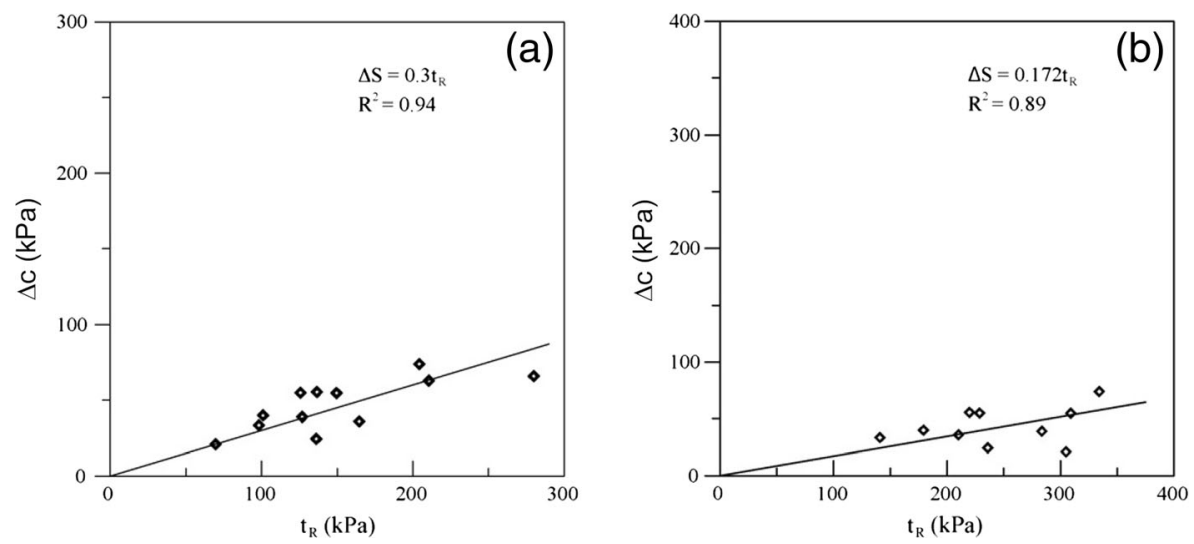

Fig. 21 The relationship between shear strength increment $(\Delta c)$ vs. tensile force of roots per unit area of the soil $\left(t_{\mathrm{R}}\right)$ on the basis of a roots crossing the shear plane and $\mathbf{b}$ all roots in a single plant (Fan and Chen [42] for ironwood species) 
branch roots, the shear failure between root and soil, or by the combinations of them $[6$, $36,17,39,76]$.

The pullout failure could occur when the available total amount of (i) shear stresses mobilized at the interface of soil-root along the length of the root and (ii) bearing stresses due to the roots' structure is lower than the applied tensile load. These concepts were explained in detail using experimental and theoretical experience gained by carrying out on geosynthetic reinforcement [77-80].

Starting with the simple hypotheses that the root grows in the soil vertically, with a constant diameter, $d$, and without lateral branches (Fig. 22), pullout force can be estimated by the following equation:

$$
\left\{\begin{array}{l}
\tau=\sigma_{\mathrm{n}}^{\prime} \cdot \tan \delta \\
\mathrm{PR}=\tau \cdot \pi \cdot d \cdot L_{\mathrm{A}}
\end{array} \Rightarrow \mathrm{PR}=\sigma_{n}^{\prime} \tan \delta \cdot \pi \cdot d \cdot L_{\mathrm{A}}\right.
$$

where $\delta$ is the interface friction angle between soil and root, $\sigma_{\mathrm{n}}^{\prime}$ is the normal stress acting on lateral surface of the root, and $L_{\mathrm{A}}$ is the active length of the root.

Therefore, the pullout force depends on the soil depth (and consequently on the $\sigma_{\text {n}}^{\prime}$ ), on the interface root-soil characteristics $(\delta)$, on the geometrical characteristics of root (d), and on the mechanical characteristic of the soil.

In the actual in situ condition, the pullout force is generally greater than as calculated by Eq. (4). The pullout force acts over a much greater root area (multiple branches), the diameter is not constant, and the tortuosity characteristic of the root embedded in the soil mass implies the mobilization of 3-D effects (i.e., mobilization of bearing resistance component: Cazzuffi et al. [81, 82]).

Field data collected by Pollen [76] showed that for roots of a given species growing in a soil of a given shear strength, at small root diameters, tensile strength exceeds pullout resistance but at larger root diameters pullout strength exceeded tensile strengths (Fig. 23). The threshold between the two failure mechanisms is a function of the shear strength of the soil (and thus of the strength of frictional bonds between the roots and soil) and of the root species tensile strength and structure.

Other in situ pullout tests performed by many authors [46, 17, 26, 40] show that generally single root without branches tend to fail in tension (i.e., tensile strength is lower than available pullout resistance) and in some cases for complete pullout of the root. Once the root is pulled out, in views of the actual decrease in root diameter along its length, the root is able to move through cavity pipes larger than its diameter so

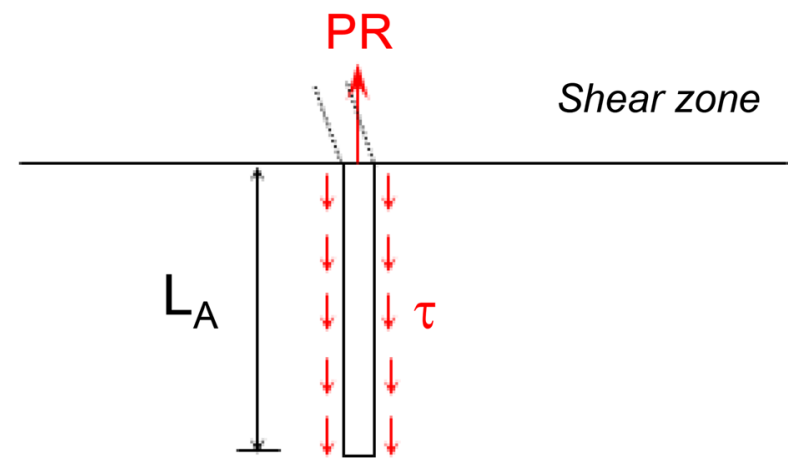

Fig. 22 Stress acting in the anchoring zone 


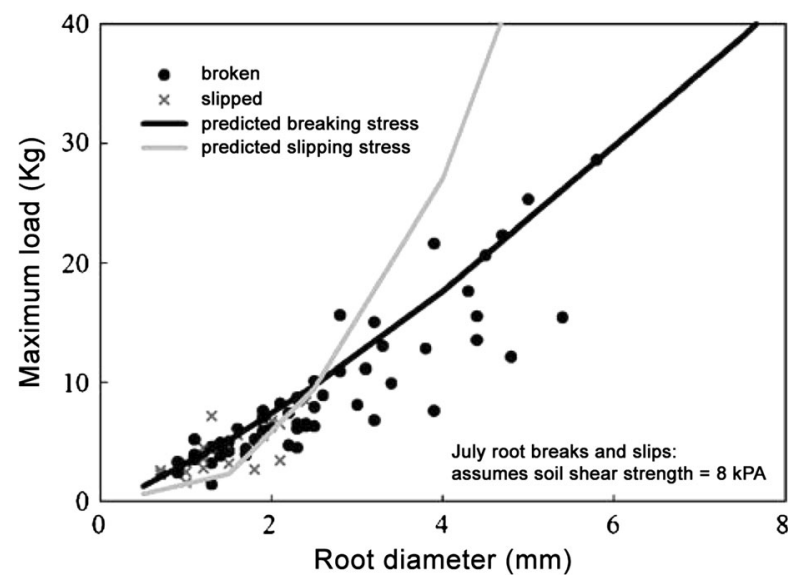

Fig. 23 Field data for root breaking and root pullout [76]

subsequently has no further interaction with the soil [17]. Experimental tests carried out on roots with multiple branches show that, in this case, the failure is generally due to the achievement of the tensile strength but tend to fail in stages as each branch breaks within the soil (Fig. 24). When a great percentage of roots fail in tension, a softening behavior is generally observed.

The experimental tests performed by Docker and Hubble [40] on larger roots show that the pullout resistance increases with the increasing of the diameter value (Fig. 25). This is probably because the larger roots tend to be better anchored in the soil (larger size and branched morphology).

Experimental studies performed by Mickovski et al. [45, 83] on simplified models of three basic root systems (i.e., taproot, herringbone pattern, dichotomous pattern) showed that the pullout resistance of root embedded in soil depends on root stiffness, pore water suction of the soil, root architecture, and root diameter.

\section{Analytical and Theoretical Models}

The contribution of plant roots to shear strength of soils has been studied analytically by many authors $[8,6,9,84]$, and generally, the reinforcement of soil by vegetation could be evaluated by either a macro model or a soil vegetation interaction model.

The choice of the model generally depends on the dimensions and spacing of the inclusions. The macro model is convenient when the dimensions and spacing of the reinforcement are small; vice versa, when plant inclusions or roots are large, and when the geometry is not uniform, the soil reinforcement interaction model is more convenient.

In the macro model, the system of root-soil is considered as a homogeneous material, whose properties are determined by tests on the reinforced soil. Therefore, the conventional stability analyses can be made with the Mohr-Coulomb expression in which a new term is included to take into account the contribution of roots to the cohesion intercept. 

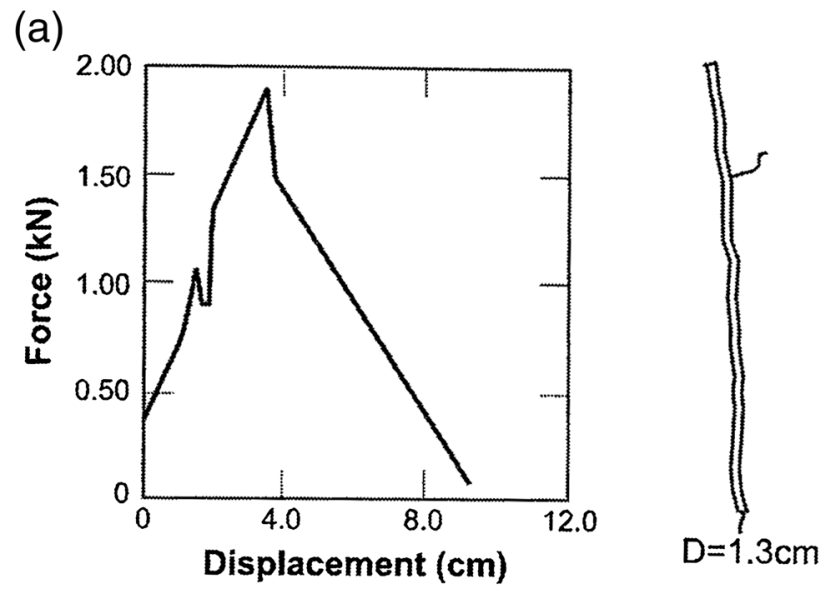

(b)
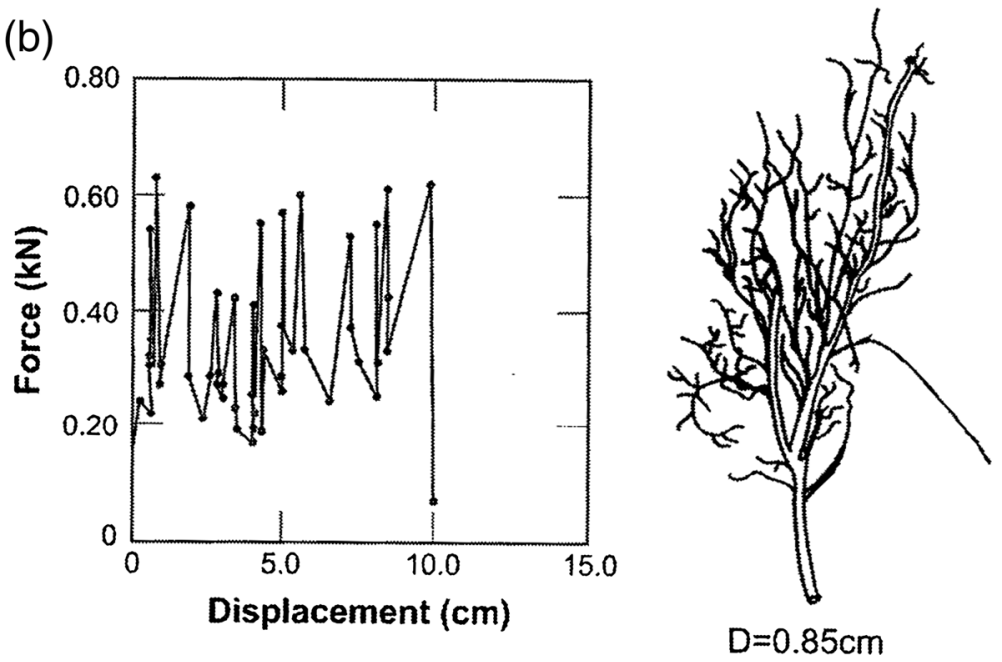

Fig. 24 Pullout test. a Single root. b Roots with multiple branches [36]

Vice versa, in the soil vegetation interaction model, the reinforcement material (root) is considered as a structural element embedded in the soil, and the forces in the reinforcement are calculated with the appropriate reinforcement properties and soil reaction. In this case, the stability analyses can be made introducing the forces in the reinforcement as boundary forces $[28,85]$, or it can be used to evaluate the additional cohesion term in the Mohr-Coulomb equation [8, 6, 86].

The second approach is generally used, and in literature, there are many soil interaction models available to evaluate the forces on reinforcement (Fig. 26) that differ according to the discretization of the soil-root system (forces on the slip surface; axial force and bending in reinforcement; solution for flexible cable; beam or pile solution; finite element method, etc.).

$\mathrm{Wu}$ [30] and Wu et al. [6] pioneered a model that was applied in numerous studies for the assessment of how roots contribute to soil shear reinforcement. The model, based on the force equilibrium principle, has been applied to both vertical roots $[30,6]$ 


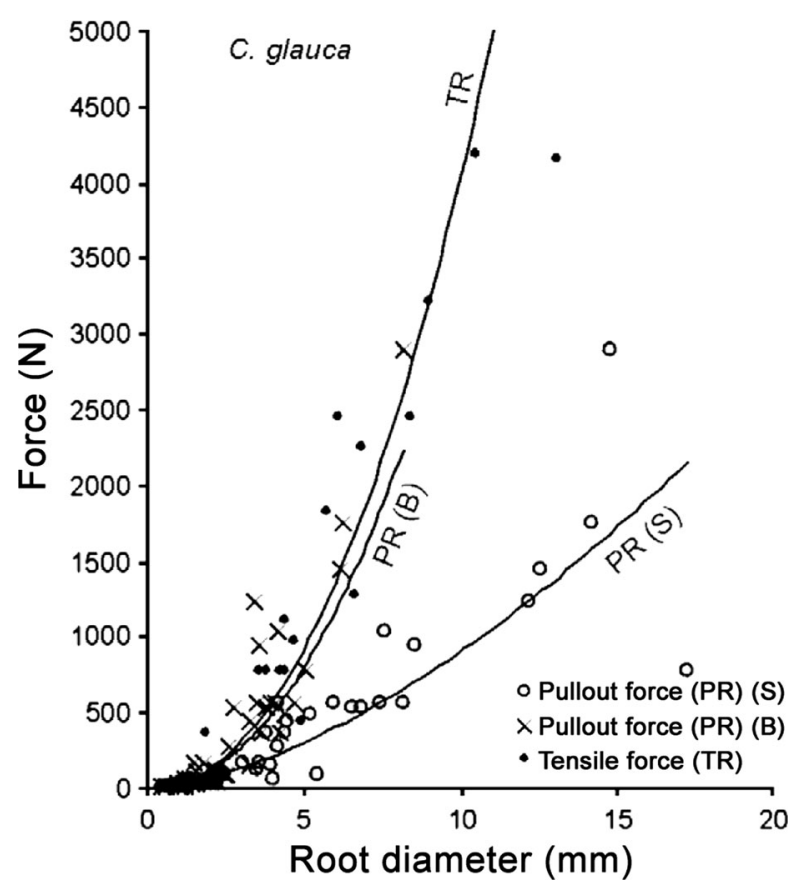

Fig. 25 In situ pullout test $(P R)$ and tensile test $(T R)$ results carried out by Docker and Hubble [40]

and inclined roots [11] and allows to evaluate the shear strength increment that can be provided by roots (Fig. 27). The deformations of the soil and the associated stresses and forces were described by $\mathrm{Wu}$ et al. [87].

Experimental results of many researchers demonstrate that the presence of roots provides a pseudo-cohesion $\Delta c$ if the mechanical behavior at failure is expressed with a Mohr-Coulomb's law, while the shear strength angle $\phi^{\prime}$ remains substantially unchanged.

So, the Mohr-Coulomb equation (Fig. 28) is normally used to evaluate the shear strength of root-reinforced soils based on three assumptions: (i) roots penetrate vertically into the soil subjected to shear and a shear zone with a thickness of $z$ remains unchanged during shear; (ii) roots are flexible, linearly elastic, and uniform in diameter; and (iii) the friction angle $\phi$, of soils is not affected by roots [8, 9].

Generally, the presence of roots has an influence on soil shear strength, in particular at failure and in the post-critical phase, making the composite material more deformable. On the contrary, in the pre-peak phase, the presence of roots, in terms of initial stiffness of the system, is not significant.

It is also commonly accepted that the presence of roots along the shear zone, where the strains are concentrated, tends to sew the two elements outside the area of process (shear zone). Then, there are two effects that are mobilized at failure, the direct one that tends to oppose to the relative movement of the two blocks outside the shear zone and, the second effect, normal to the shear plane that tends to increase the resistance associated to superficial friction.

Therefore, because of the small diameter of roots and then the low value of the moment of inertia, the bending stiffness of the individual element is practically 


\section{Forces on reinforcement}

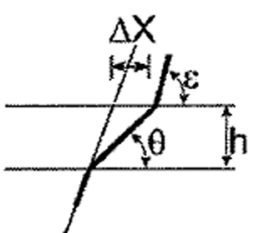

(a) forces on the slip surface shear zon deformation

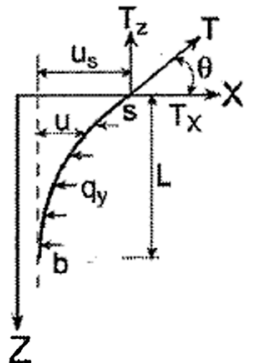

(b) Axial force and bending in reinforcement deformed bar

(1)
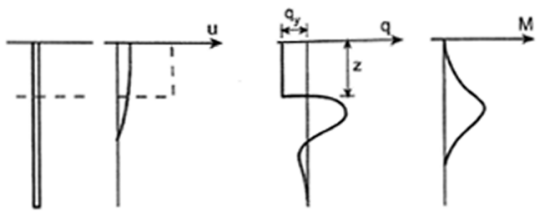

(2)

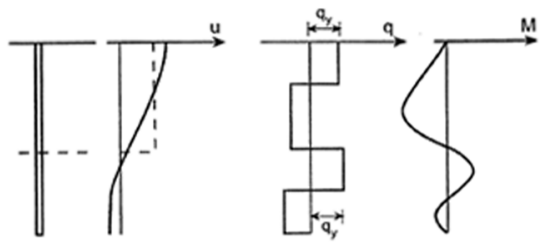

(3)
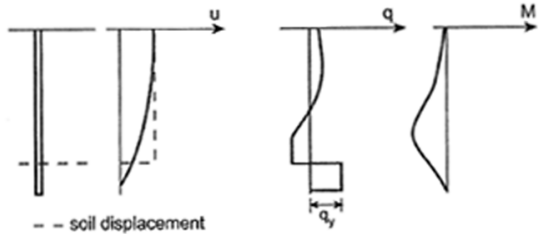

(c) beam or pile solution

failure modes for live poles:

(1) flow mode; (2) long-pile mode; (3) short-pile mode.

Fig. 26 Soil reinforcement interaction models: the forces on reinforcement

negligible, and it is clear that the single element works in large displacements, exactly like a cable.

Using the scheme in Fig. 27a, the force equilibrium models developed by Waldron [8] and Wu et al. [6] allow to compute the additional shear strength, $\Delta c$, for vertical roots with the following equation:

$$
\Delta c=t_{R}(\sin \theta+\cos \theta \tan \phi)
$$

where $t_{\mathrm{R}}$ is the mobilized tensile force in roots per unit area of soil, $\theta\left(=\tan ^{-1} x / z\right)$ is the angle of the root relative to vertical after shear distortion, $z$ is the thickness of the shear 


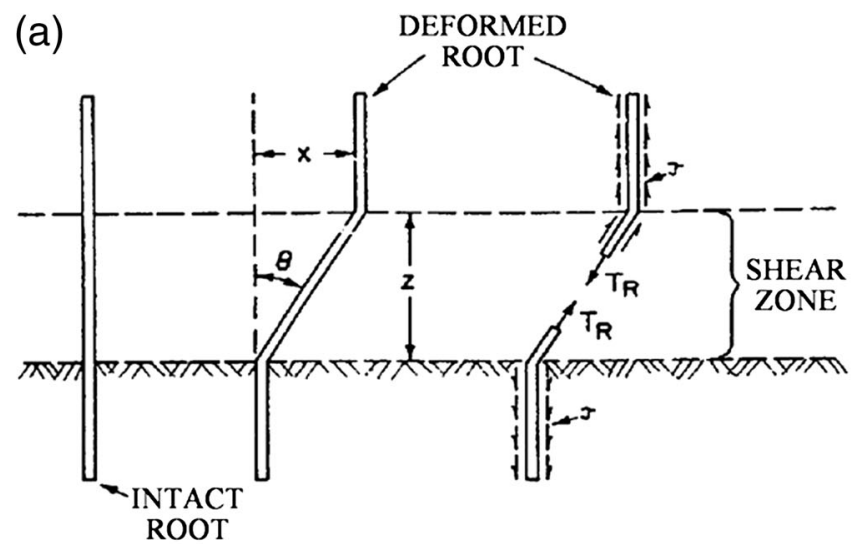

(b)

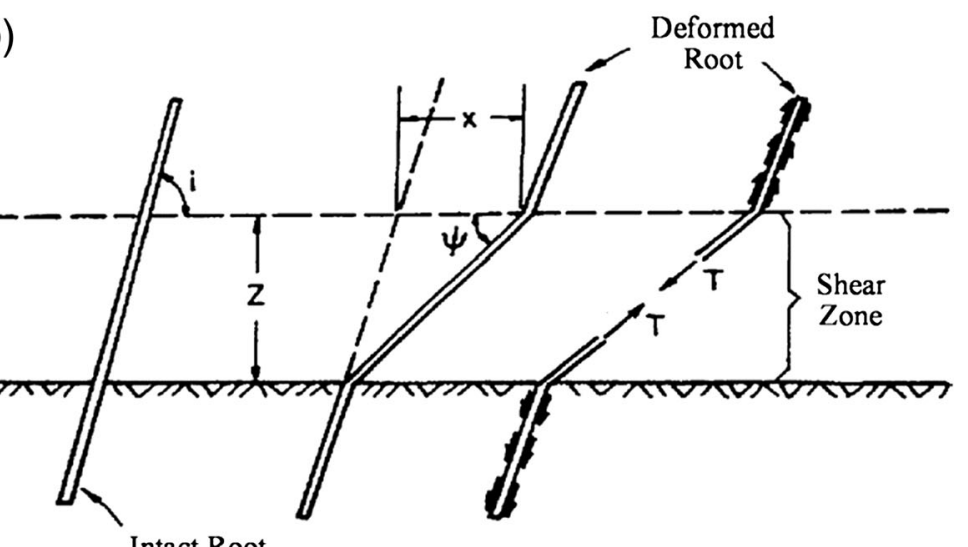

Intact Root

Fig. 27 Root reinforcement models. a Perpendicular root reinforcement model $[8,6]$. b Inclined root reinforcement model [11]

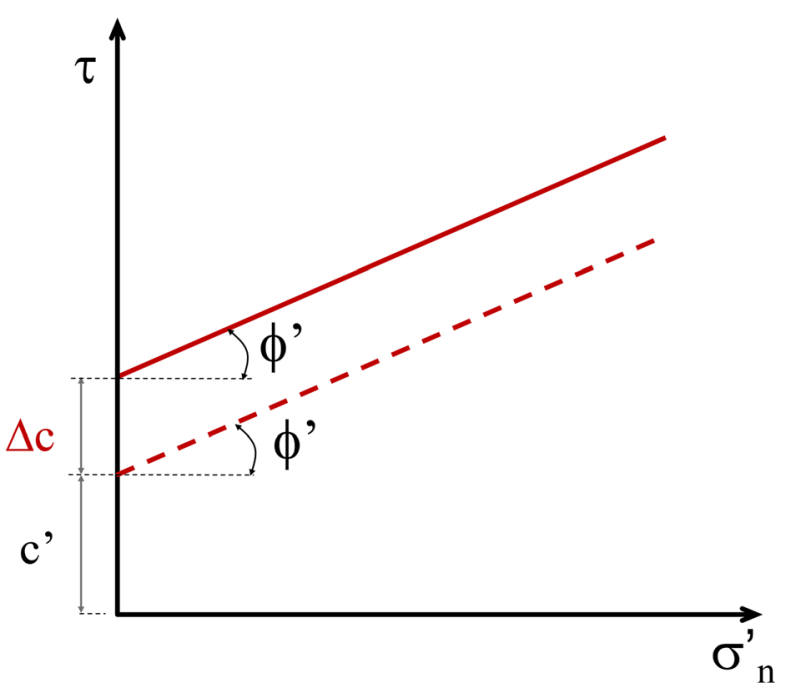

Fig. 28 Root effects on soil shear strength behavior: Mohr-Coulomb's law 
zone, and $x$ is the shear displacement. The mobilized force in roots is dependent on elongation and fixity of roots in soils.

The mobilized tensile force in roots per unit area of soil, $t_{\mathrm{R}}$, can be computed by the following equation:

$$
t_{\mathrm{R}}=T_{\mathrm{R}} \frac{A_{\mathrm{R}}}{A}
$$

where $T_{\mathrm{R}}$ is the tensile stress developed in roots, $A$ is the area of the soil shear surface, $A_{\mathrm{R}}$ is the total cross-sectional area of all roots crossing the shear surface, and $A_{\mathrm{R}} / A$ is defined as the RAR.

Based on experimental results, $\mathrm{Wu}$ et al. [6] observed that the value of the term $(\sin \theta+\cos \theta \tan \phi)$ in Eq. (1) is relatively insensitive to the normal variations in $\theta(=40$ $\left.90^{\circ}\right)$ and $\phi\left(=25-40^{\circ}\right)$. Therefore, Wu et al. [6] proposed an average value of 1.2 for this term, avoiding to assess the value of the angle $\theta$.

$$
\Delta c \cong 1.2 \cdot t_{\mathrm{R}}
$$

So, if roots are anchored in soil without pulling out such that the tensile strength of all roots is fully mobilized, the value of $\Delta c$ can be readily evaluated based on the tensile strength of roots.

Gray and Leiser [11] analyzed the additional shear strength provided by root reinforcement for a root inclined from the vertical (Fig. 2b). In this case, the additional shear strength provided by roots can be estimated by the following equation:

$$
\Delta c=t_{R}[\sin (90-\psi)+\cos (90-\psi) \tan \phi]
$$

where $\psi$ is angle of shear distortion and is expressed $\operatorname{as}^{-1}\left[1 /\left(m+(\tan i)^{-1}\right)\right]$, $i$ is the initial angle of inclination with respect to shear surface, and $m$ is shear distortion ratio $(m=x / z)$.

Parametric analysis carried out by Gray and Leiser [11] suggested that the optimal orientation for roots to provide the additional shear strength appears in an inclination between $40^{\circ}$ and $70^{\circ}$ rather than in a vertical orientation, and for soils with a friction angle of $30^{\circ}$, the optimal value for the bracketed term in Eq. (8) is about 1.15 .

Figures 29, 30, and 31 show the increase in shear strength calculated according to the model of Waldron [8] and $\mathrm{Wu}$ et al. [6] in a research started in Italy by CESI in

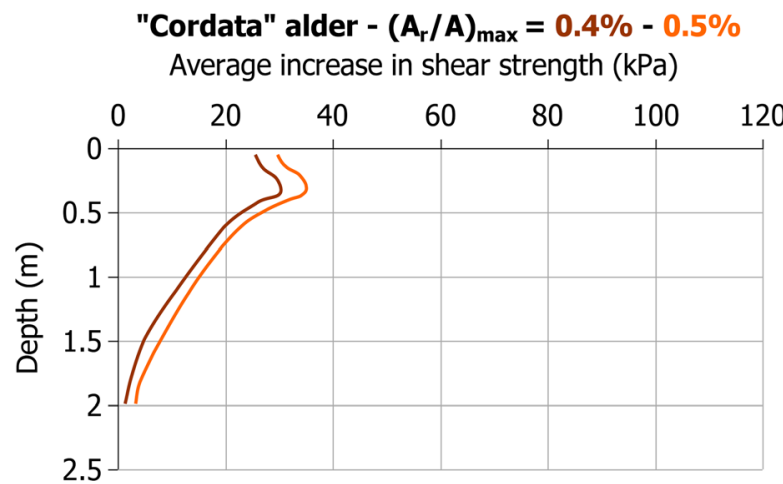

Fig. 29 Increase in shear strength $(\mathrm{kPa})$ vs. depth (m) for "cordata" alder, considering both values of $A_{\mathrm{R}} / A$ of 0.4 and $0.5 \%$ 


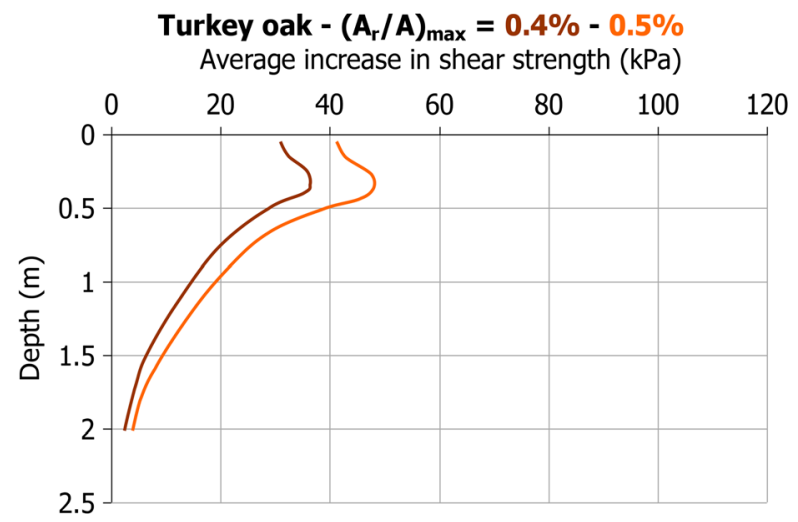

Fig. 30 Increase in shear strength (kPa) vs. depth (m) for turkey oak, considering both values of $A_{\mathrm{R}} / A$ of 0.4 and $0.5 \%$

Milan [57] carried out on different species of plants commonly used for slope stabilization. The research concerned both native (cordata alder, turkey) and imported species (Elygrass, Pangrass, Vetiver) for different values of RAR.

The model of Waldron [8] and $\mathrm{Wu}$ et al. [6] relies on the assumptions that all roots are fully mobilized during soil shearing and that all roots break at the same time, whereas in reality, roots break progressively. Consequently, it estimates maximum values of $\Delta c$, and generally, these values overestimate root reinforcement $[13,39$, 88 ]. A reducing factor equal to 0.5 is then commonly applied to the calculated increase of shear strength to take into account that root strength is not mobilized simultaneously in the whole soil mass.

Once the increase of shear strength vs. depth is obtained, stability analysis on the different slopes encountered on site is performed, introducing into the model the soil properties determined by geotechnical testing.

Figures 32, 33, and 34 show the slope safety factor curve vs. depth for the vegetated soil and the non-vegetated soil [57] obtained by using classical slice methods, analyzing both rotational and planar failure mechanisms.

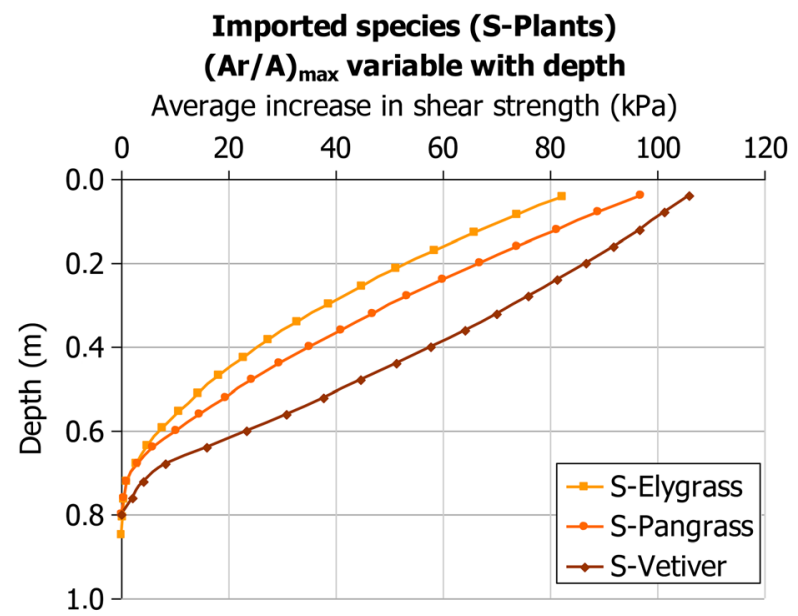

Fig. 31 Increase in shear strength $(\mathrm{kPa})$ vs. depth $(\mathrm{m})$ for imported species sampled on site (S-Plants) 


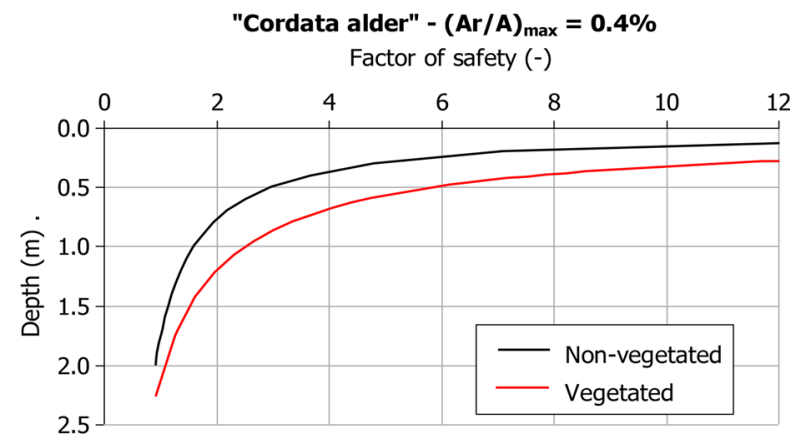

Fig. 32 Cordata alder: slope safety factor curve vs. depth for vegetated and non-vegetated soil [57]

On this subject, it is useful to remark that the identification of potential failure surface depends mainly on the slope geometry, on the mass distribution, and on the soil strength parameters, so it is hardly influenced by root presence, especially when the shear zone is relatively deep. Thus, it is possible to affirm that vegetation can effectively contribute to soil stabilization only if the failure surface concerns superficial soil masses, typically for depths of up to $2 \mathrm{~m}$.

In order to evaluate quantitatively the mechanical contribution of vegetation to slope stability, in particular in the presence of cohesive soils, a theoretical model was developed by CESI, in collaboration with Politecnico di Milan. This study regards the interpretation of the mechanical behavior of soft ground reinforced by root systems and aims to analyze and better understand the macro effect of the presence of root systems in the mechanical response of soil specimens in direct shear test condition. In particular, the focus is the analysis of the micro factors (soil-root interaction) that affect the shear strength of the reinforced rooted soil in order to identify useful tools for the design of stabilization systems.

The theoretical model is able to determine the increase in shear strength, due to the presence of the roots, as an increase in soil cohesion.

The root system is characterized by tensile strength far from negligible: it follows that a fraction of the shear stress (which is subject to the solid matrix) can be transferred to the roots in the form of shear stress. However, this mechanism is activated so that it is

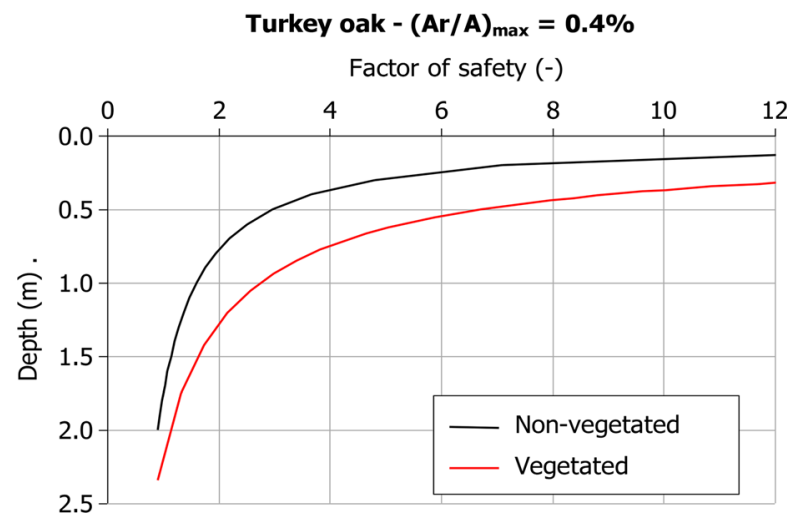

Fig. 33 Turkey oak: slope safety factor curve vs. depth for vegetated and non-vegetated soil [57] 


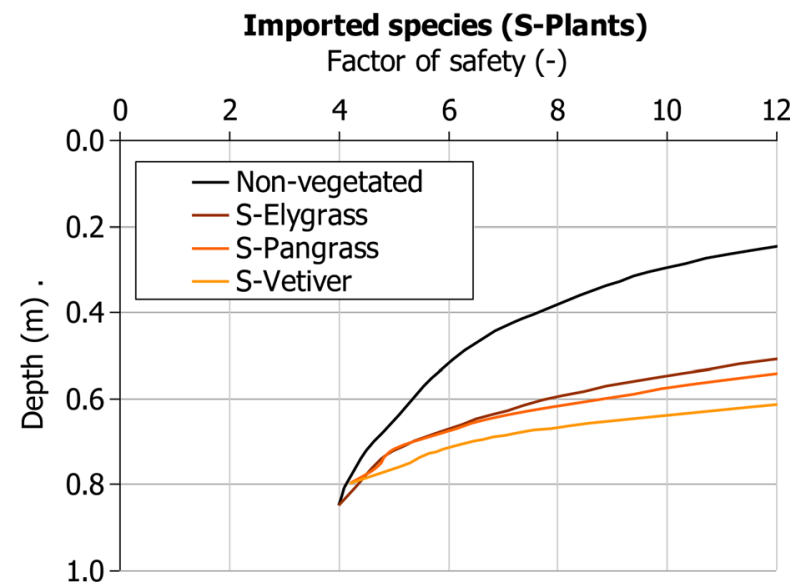

Fig. 34 Imported species: slope safety factor curve vs. depth for the vegetated and non-vegetated soil [57]

necessary that the inclusion is likely to deform, which is of fundamental importance, for the evaluation of the behavior of the root, determining the deformed shape.

The theoretical model was developed on the basis of the direct shear box test model and in particular on the development of the following equations: elastic line equation; equilibrium equation; principle of virtual works; and deformed root equation. By solving these four equations, it is possible to define a constitutive law for a soil reinforced with roots. The equations, which control the root system theoretical behavior, are defined idealizing the reinforcing members (roots) as cables, in a direct shear test model.

As the soil deforms, tensile stress tends to accumulate in the roots, and the final result is an increase in the shear strength of the soil due to the presence of the roots.

In the direct shear test model, three areas can be identified (Fig. 37a):

- In areas 2 and 3, there is not any relative displacement between root and soil: both areas are subjected to a rigid translation. In these areas, the root develops a tensile force, which allows its anchorage: so, the presence of roots allows to join the areas above and below the shear band.

- In area 1 , the deformation of the root allows to mobilize its tensile strength.

The same three areas identified in a direct shear box tests model could be identified in a real case on a slope (Fig. 37b).

Using Fig. 35 and 36, it is possible to evaluate the force Tp using the following system:

$$
\begin{aligned}
& \left\{\begin{array} { l } 
{ N _ { \mathrm { P } } = \sigma _ { \mathrm { VP } } A _ { \mathrm { P } } - T \operatorname { s i n } \vartheta ^ { * } } \\
{ T _ { \mathrm { P } } = \tau _ { \mathrm { P } } A _ { \mathrm { P } } + T \operatorname { c o s } \vartheta ^ { * } } \\
{ \tau _ { \mathrm { P } } = \sigma _ { \mathrm { VP } } \operatorname { t a n } \varphi }
\end{array} \Rightarrow \left\{\begin{array}{l}
\sigma_{\mathrm{VP}}=\frac{N_{\mathrm{P}}}{A_{\mathrm{P}}}+\frac{T}{A_{\mathrm{P}}} \sin \vartheta^{*} \\
T_{\mathrm{P}}=\sigma_{\mathrm{VP}} A_{\mathrm{P}} \tan \varphi+T \cos \vartheta^{*}
\end{array}\right.\right. \\
& \Rightarrow T_{\mathrm{P}}=\left(\frac{N_{\mathrm{p}}}{A_{\mathrm{P}}}+\frac{T}{A_{\mathrm{P}}} \sin \vartheta^{*}\right) A_{\mathrm{P}} \tan \varphi+T \cos \vartheta^{*}
\end{aligned}
$$

where $A_{\mathrm{P}}$ is the specimen area; $\sigma_{\mathrm{VP}}$ and $\tau_{\mathrm{P}}$ are, respectively, the vertical and the shear stress acting on the shear plane; $\phi^{\prime}$ is the soil shear strength angle; $\theta^{*}$ is the inclination 

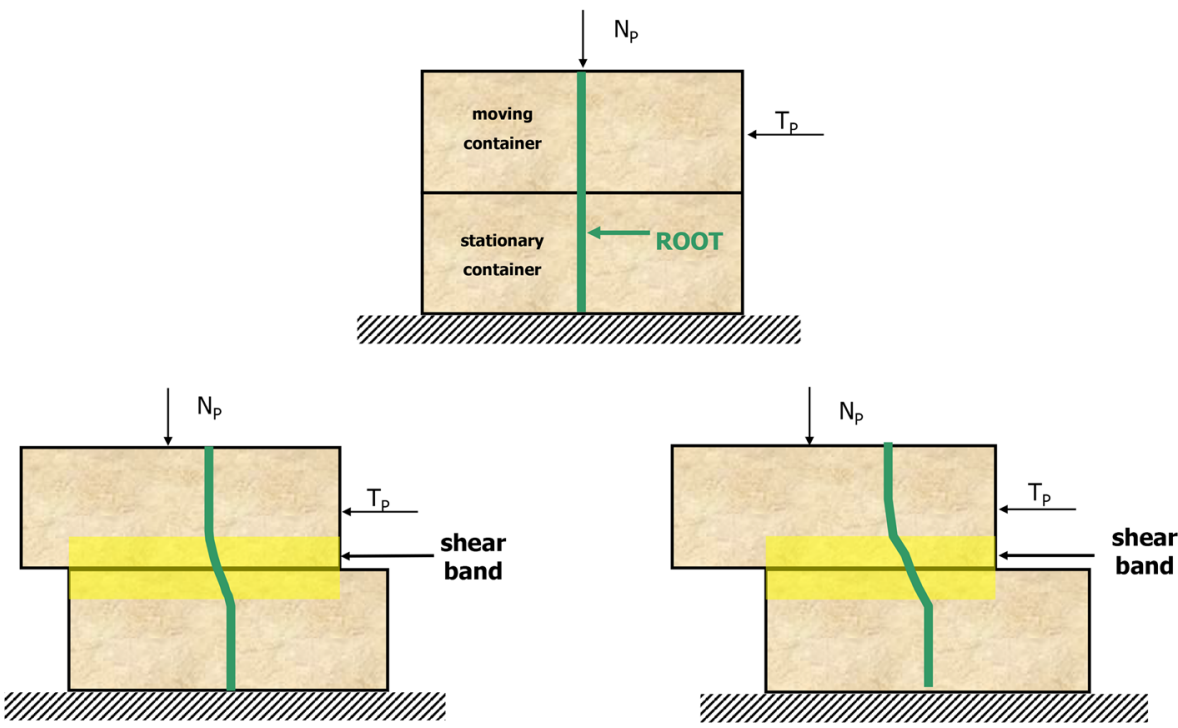

Fig. 35 Schematic of the theoretical model developed on the basis of the direct shear box test model

of the deformed root respect to the shear plane; and $T$ is the tensile force acting on the root.

Assuming that the homogenized soil area and the solid matrix area are the same (i.e., area of the roots is negligible), and assuming that the diameter of the inclusions is constant, the shear stress is equal to:

$$
\left\{\begin{array}{l}
\tau_{\mathrm{P}}=\sigma_{\mathrm{VP}} \tan \varphi^{\prime}+N \sigma_{\mathrm{R}} \rho\left(\sin \vartheta^{*} \tan \varphi^{\prime}+\cos \vartheta^{*}\right) \\
\sigma_{\mathrm{R}}=\frac{T}{A_{\mathrm{R}}}
\end{array} \Rightarrow \tau_{\mathrm{P}}=\sigma_{\mathrm{VP}} \tan \varphi^{\prime}+\Delta c\right.
$$

where $N$ is the number of roots; $\sigma_{\mathrm{R}}=$ root tensile stress; $\rho=A_{\mathrm{R}} / A_{\mathrm{P}}$ is the rate rooted area $\left(A_{\mathrm{R}}\right)$ and specimen area $\left(A_{\mathrm{P}}\right)$; and $\Delta c$ is the increase in cohesion due to the presence of the root.

The system shows that a vegetated soil behaves exactly as a friction material (MohrCoulomb type) that has an additional cohesion $\Delta c$, provided by inclusions, which allows the material to withstand tensile stress.

In the previous simple force equilibrium models [6, 9], the zone in which the inclusion is deformed matches the shear zone, and the introduction of this restrictive assumption allows to reduce the indeterminacy of the problem to the single evaluation of the inclination of the deformed root respect to the shear plane $\theta^{*}$, while in proposed

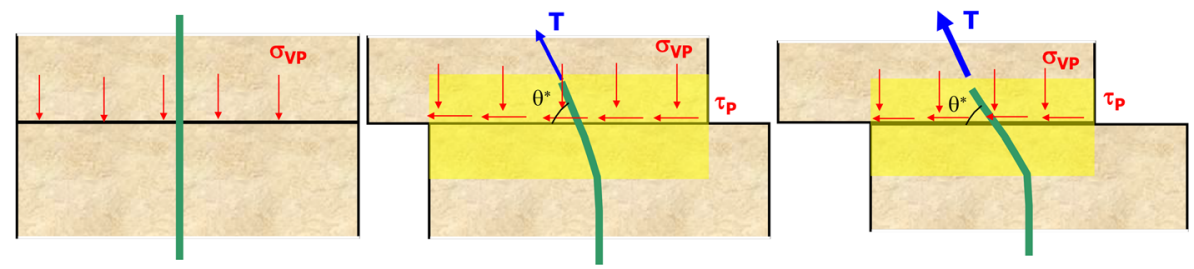

Fig. 36 Particular of the shear test box: the shear band 

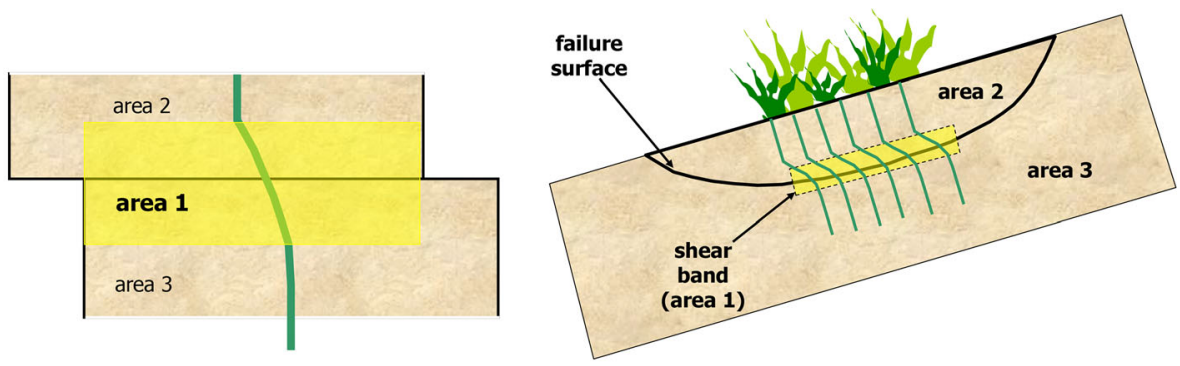

(a) shear box

(b) slope

Fig. 37 Different areas in the case of $\mathbf{a}$ direct shear test model and $\mathbf{b}$ real case on a slope

theoretical model, the deformation zone of the root (area 1, Fig. 37) is greater than the shear band. In this case, to evaluate the tensile force acting on the root, $T$, and the strains along the inclusion, an alternative solution based on the similarity between root in shear test condition and a cable of length $L$ hinged at the ends and subjected to a load $q$ is used (Fig. 38a).

In Fig. 38b, considering only the portion below the same plane, the portion $\mathrm{ABC}$ represents the deformed shape of cable: the stretch $\mathrm{AC}$ (in red) represents the behavior of the inclusion, while the stretch of the cable CB (in blue), it is only an artifice useful to the resolution of the problem (after point $\mathrm{C}$, in fact, the root does not undergo deformation). The length of deformed inclusion is therefore equal to $0.5 \mathrm{~L}$.

Using the equations of equilibrium, the principle of virtual work, and the shape of the deformed root, it is possible to evaluate, for each depth, the value of the components in horizontal and vertical direction of the tensile force, $T$, acting on the root and therefore its inclination with respect to the horizontal plane, $\theta$.

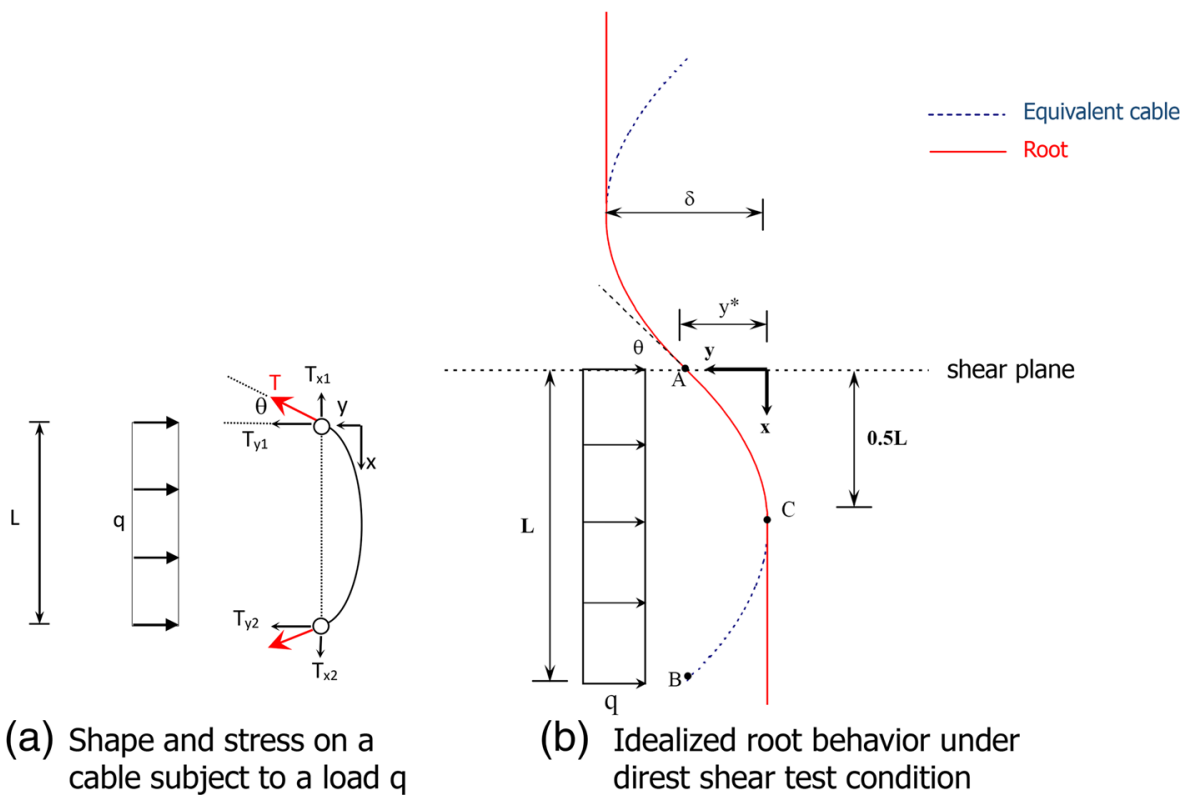

Fig. 38 Idealized root behavior under direct shear condition 
Table 2 Theoretical model: input parameters

Input parameters

Soil

Roots

$\gamma_{\text {soil }}=$ unit weight

Rooted area vs. shear plane depth

$\phi^{\prime}=$ friction angle

Diameter distribution at the depth of the shear plane

$c^{\prime}=$ cohesion

Tensile strength vs. diameter

$z=$ shear plane depth

$E=$ root elastic modulus, calculated from the results of tensile tests on roots

The theoretical model can calculate the contribution $\Delta c$ of roots to the increase in soil shear strength requiring as input with a limited number of parameters taking into account the type of soil and of the characteristics of the different species of vegetation. The model is also able to take into account the confining pressure, the stiffness of the surrounding soil, and the post-peak behavior of soil reinforced. Table 2 shows the required input parameters in the proposed theoretical model for the soil and the roots.

To test its reliability, the theoretical model was applied to the direct shear tests performed by CESI on the specimens containing the different types of gramineous species. Figure 39a shows the comparison between shear tests conducted on soil and rooted soil with Vetiver. Figure 39b shows the comparison between experimental results and the theoretical model in term of increase in soil cohesion, $\Delta c$.

A parametric analysis was also carried out by varying diameter distribution: five typical diameters were considered and a different number of roots was assigned to each diameter. The results seem to be in very good agreement with the experimental results (Fig. 40).

More recently, fiber bundle models have been utilized by Pollen and Simon [39], with roots viewed as fibers bearing load with load redistributed as fibers break [89] resulting in progressive failure. On the other hand, $\mathrm{Wu}$ et al. [6] assumed that roots fail

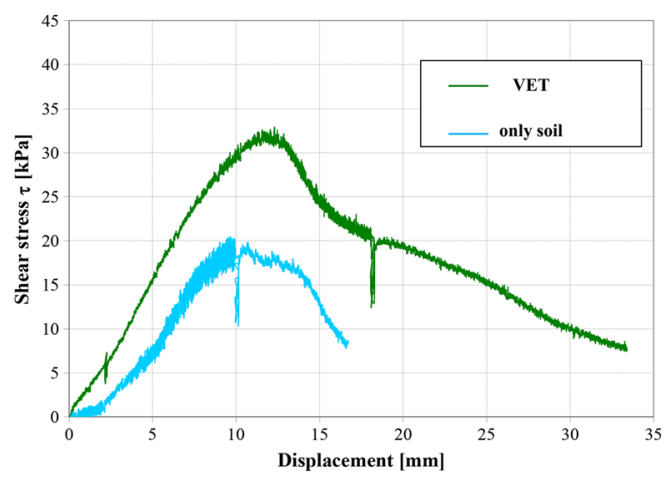

(a) Direct shear test results

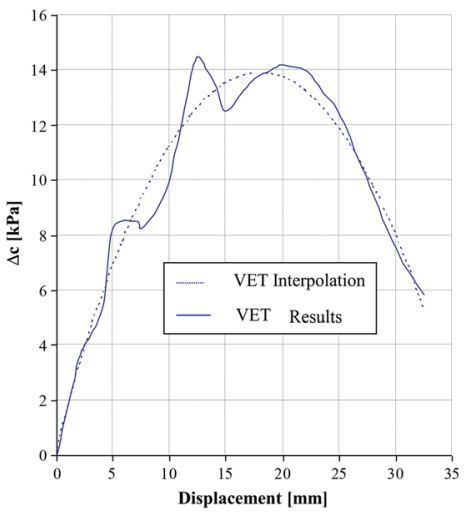

$\Delta \mathrm{c}=\tau_{\text {vet }}-\tau_{\text {soil }}$

(b) Comparison between experimental results and the proposed theoretical model

Fig. 39 Validation of proposed theoretical model. a Direct shear test results. b Comparison between experimental results and the theoretical model 


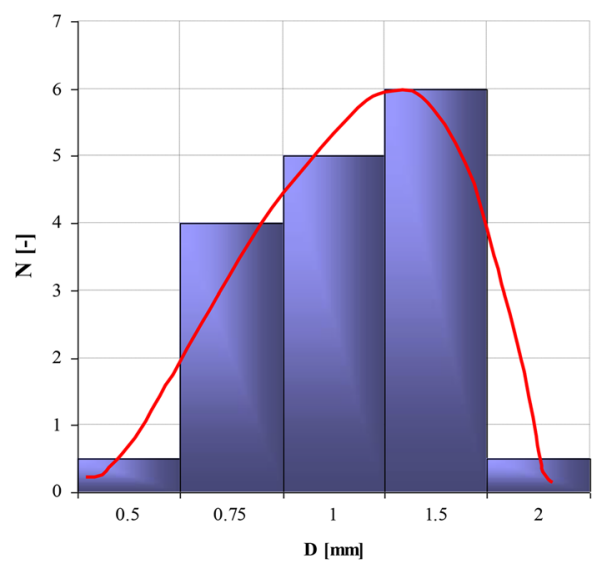

(a) Example of diameter distribution of Vetiver root system

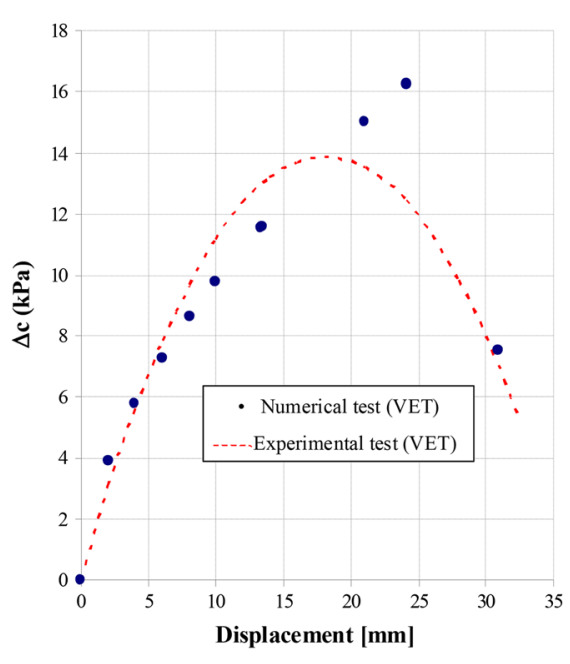

(b) Comparison between experimental results and the proposed theoretical model

Fig. 40 Parametric analysis by varying diameter distribution. a Example of diameter distribution of Vetiver root system. b Comparison between experimental and theoretical increase in soil cohesion

catastrophically (i.e., all at the same time), with soil strength heavily reliant on the RAR. The fiber bundle model (FBM) proposed by Pollen and Simon [39] used the relationship between root diameter and strength to describe progressive failure of roots from weakest to strongest. In the FBM, load is redistributed as each root breaks, and probably this approach is more realistic as progressive failure has been observed in the failure of root systems [88]. The application of the FBM for the estimation of root reinforcement proposed by Pollen and Simon [39] has emerged as a useful representation of mechanical and geometrical characteristics of plant root systems. Although Waldron [8] and $\mathrm{Wu}$ et al. [6] model is not the most accurate and realistic one, it remains one of the most widespread model for preliminary root reinforcement assessment because it is more simple and requires less input data than the above-mentioned models.

\section{Conclusions}

Considering that the use of vegetation for slope stabilization has grown in importance, specific design standards are still under discussion. Therefore, the design and the management of stabilization systems by plants require an accurate knowledge about the quantitative reinforcing root effects on soil strength, estimable by using in situ tests (e.g., direct shear tests and pullout tests) and laboratory tests (e.g., tensile tests and direct shear tests) for modelling the root-soil interactions. This paper presents the conclusions drawn on the specific role of vegetation in soil reinforcement applications by the use of a huge amount of experimental in situ and laboratory data.

The increase in soil strength by means of roots involves compound mechanisms due to the multitude of quite complex interactions between roots and soil. The 
reinforcement magnitude depends on several factors but mostly on the root distribution and strength properties.

Root tensile strength testing is a crucial step to evaluate root reinforcement. Experimental results carried out by many researchers show a great variability among the different species and for the same species. The cellulose and the lignin content and tensile strength of roots could be significantly correlated but the variability was large.

In order to quantify the contribution of roots on the soil mechanical properties, direct shear test on undisturbed samples containing only soil and soil with roots, respectively, will be carried out in laboratory. Generally, soil improved by using root reinforcement involves only an increase in term of cohesion, while the shear strength angle of both the reinforced and unreinforced soil did not change in a systematic manner. The contribution of roots to the soil shear strength is evident: (i) the shear strength values of soil samples with roots are always higher than the values obtained from tests performed on soil samples without roots and (ii) increase linearly with the increasing of the vertical pressure.

The ultimate mobilized root strength depends on the root failure mode (pullout failure or tensile strength failure) of the root-reinforced soil. If the tensile strength failure does not occur, the pullout failure could take place when the available total amount of (i) shear stresses mobilized at the interface of soil-root along the length of the root and (ii) bearing stresses due to the roots structure is lower than the applied tensile load.

In situ pullout test results performed by different researchers show that generally for roots of a given species growing in a soil of a given shear strength, at smaller root diameters, the tensile strength exceeds the pullout resistance, but at larger root diameters, the pullout strength exceeds the tensile ones. The threshold between the two failure mechanisms is a function of the shear strength of the soil (and thus of the strength of frictional bonds between the roots and soil) and tensile strength and structure of the root species. Generally, the pullout resistance increases with the increase of the diameter value.

In literature, there are various analytical and theoretical models in order to estimate the increase in soil shear strength of rooted soil and the models could give satisfactory results if required parameters are available.

In order to evaluate quantitatively the mechanical contribution of vegetation to slope stability, in particular in presence of cohesive soils, a theoretical model was developed by CESI, in collaboration with Politecnico of Milan. This study regards the interpretation of the mechanical behavior of soft ground reinforced by root systems and aims to analyze and better understand the macro effect of the presence of root systems in the mechanical response of soil specimens in direct shear test condition. In particular, the focus has been on the analysis of the micro factors (soil-root interaction) that affect the shear strength of the reinforced rooted soil in order to identify useful tools for the design of stabilization systems. The theoretical model is able to determine the increase in shear strength, due to the presence of roots, as an increase in soil cohesion.

Although the simple method is not the most accurate and realistic one, it remains one of the most widespread models for preliminary root reinforcement assessment because it is simpler and does not require extensive input data. 


\section{References}

1. Schiechtl, H.M.: Grundlagen der Grunverbauung. Mitteilungen der Forstlichen bundes-versuchsanstalt. Mariabrunn 55, 273 (1958)

2. Schiechtl, H.M.: Bioengineering for Land Reclamation and Conservation. University of Alberta Press, Edmonton (1980)

3. Endo, T., Tsuruta, T.: Effects of tree roots on the shearing strength of soil. In: 18th Annual Report of the Hokkaido Branch, Government Forest Experimental Station. pp. 167-179. Tokyo, (1969)

4. Megahan, W.F., Kidd, W.J.: Effect of logging roads on sediment production rates in the Idaho Batholith. In: Intermountain Forest \& Range Experiment Station, vol. Res. Pap. INT-123. Forest Service, U.S. Dept. of Agriculture, Ogden, Utah, (1972)

5. O'Loughlin, C.: The effect of timber removal on the stability of forest slopes. J. Hydrol. 13, 121-134 (1974)

6. Wu, T.H., Mckinnell, W.P., Swanston, D.N.: Strength of tree roots and landslides on Prince of Wales Island, Alaska. Can. Geotech. J. 16, 19-33 (1979)

7. Wu, T.H., Watson, A.: In situ shear tests of soil blocks with roots. Can. Geotech. J. 35(4), 579-590 (1998)

8. Waldron, L.J.: The shear resistance of root-permeated homogeneous and stratified soil. Soil Sci. Soc. Am. J. 41(5), 843-849 (1977)

9. Waldron, L.J., Dakessian, S.: Soil reinforcement by roots: calculation of increased soil shear resistance from root properties. Soil Sci. 132(6), 427-435 (1981)

10. Ziemer, R.R.: Roots and the stability of forested slopes. In: Erosion and Sediment Transport in Pacific Rim Steeplands. International Association of Hydrological Sciences. 132, 343-361 (1981)

11. Gray, D.H., Leiser, A.T.: Biotechnical slope protection and erosion control. Van Nostrand Reinhold Company (1982)

12. Greenway, D.R.: Vegetation and Slope Stability. Wiley, New York (1987)

13. Operstein, V., Frydman, S.: The influence of vegetation on soil strength. Ground Improv. 4, 81-89 (2000)

14. Cofie, P., Koolen, A.J.: Test speed and other factors affecting the measurements of tree root properties used in soil reinforcement models. Soil Tillage Res. 63(1-2), 51-56 (2001)

15. Schmidt, K.M., Roering, J.J., Stock, J.D., Dietrich, W.E., Montgomery, D.R., Schaub, T.: The variability of root cohesion as an influence on shallow landslide susceptibility in the Oregon Coast Range. Can. Geotech. J. 38, 995-1024 (2001)

16. Roering, J.J., Schmidt, K.M., Stock, J.D., Dietrich, W.E., Montgomery, D.R.: Shallow landsliding, root reinforcement, and the spatial distribution of trees in the Oregon Coast Range. Can. Geotech. J. 40(2), 237-253 (2003)

17. Norris, J.E.: Root reinforcement by hawthorn and oak roots on a highway cut-slope in Southern England. Plant Soil 278(1), 43-53 (2005)

18. Coppin, N.J., Richards, I.G.: Use of Vegetation in Civil Engineering. Butterworth-Heinemann, London (1990)

19. Gray, D.H., Sotir, R.B.: Biotechnical and Soil Bioengineering Slope Stabilization: A Practical Guide for Erosion Control. J. Wiley \& Sons New York, U.S.A. (1996)

20. Schiechtl, H.M., Stern, R.: Water Bioengineering Techniques. Blackwell Sdence, Oxford (1997)

21. Swanston, D.N.: Slope stability problems associated with timber harvesting in mountainous regions of the western United States. In: USDA Forest Service General Technical Report vol. PNW-2L. (1974)

22. Gray, D.H., Megahan, W.F.: Forest vegetation removal and slope stability in the Idaho Batholith. In: Intermountain Forest and Range Experiment Station, U.S. Forest Service, Ogden, Utah (1981)

23. Tsukamoto, Y., Kusaba, O.: Vegetative influence on debris slide occurrences on steep slopes in Japan. In: Symposium on Forest Land Use on Erosion and Slope Stability, Honolulu, Hawaii 1984. Environmental Policy Institute

24. Burroughs, E.R., Thomas, B.R.: Declining root strength in Douglas-fir after felling as a factor in slope stability. In: Intermountain Forest and Range Experiment Station. Forest Service, U.S. Dept. of Agriculture (1977)

25. Loades, K.W., Bengough, A.G., Bransby, M.F., Hallett, P.D.: Planting density influence on fibrous root reinforcement of soils. Ecol. Eng. 36(3), 276-284 (2010)

26. Abernethy, B., Rutherfurd, I.D.: The distribution and strength of riparian tree roots in relation to riverbank reinforcement. Hydrol. Process. 15(1), 63-79 (2001)

27. Sidle, R.C.: A conceptual model of changes in root cohesion in response to vegetation management. J. Environ. Qual. 20, 43-52 (1991) 
28. Wu, T.H.: Effect of vegetation on slope stability. In: Soil Reinforcement and Moisture Effects on Slope Stability. pp. 37-46. Transportation Research Board, (1984)

29. Wu, T.H., Sidle, R.C.: A distributed slope stability model for steep forested basins. Water Resour. Res. 31(8), 2097-2110 (1995)

30. Wu, T.H.: Investigation of landslides on Prince of Wales Island, Alaska. In: Geotechnical Engineering Report 5. Department of Civil Engineering, Ohio State University, Columbia, Ohio, (1976)

31. Bischetti, G.B., Chiaradia, E.A., Simonato, T., Speziali, B., Vitali, B., Vullo, P., Zocco, A.: Root strength and root area ratio of forest species in Lombardy (Northern Italy). Plant and Soil (2005).

32. Burkle, M.K., Raynal, D.J.: Fine root growth phenology, production and turnover in a northern hardwood forest ecosystem. Plant Soil 162, 135-146 (1994)

33. Schmid, I., Kazda, M.: Vertical distribution and radial growth of coarse roots in pure and mixed stands of Fagus sylvatica and Picea abies. Can. J. For. Res. 31(3), 539-548 (2001)

34. Böhm, W.: Methods of studying root systems. In: Ecological Studies, vol. Series no. 33. Springer-Verlag, Berlin (1979)

35. Vogt, K.A., Persson, H.: Measuring Growth and Development of Roots. Techniques and Approaches in Forest Tree Ecophysiology. CRC Press, Boca Raton (1991)

36. $\mathrm{Wu}$, T.H.: Root reinforcement of soil: review of analytical models, test results, and applications to design. Can. Geotech. J. 50(3), 259-274 (2013)

37. Cazzuffi, D., Tironi, F.: Contribution of roots to slope stability: an overview of typical results for different plants. In: Fast Slope Movements: Prediction and Prevention for Risk Mitigation, Naples, 11-13 May 2003

38. Reinstenberg, M.M.: Anchoring of thin collovium by roots of sugar maple and with ash on hillslopes in Cincinnati. United States Geological Survey 2059-E (1994).

39. Pollen, N., Simon, A.: Estimating the mechanical effects of riparian vegetation on stream bank stability using a fiber bundle model. Water Resources Research, 41 (2005).

40. Docker, B.B., Hubble, T.C.T.: Quantifying root-reinforcement of river bank soils by four Australian tree species. Geomorphology 100(3-4), 401-418 (2008)

41. Schwarz, M., Preti, F., Giadrossich, F., Lehmann, P., Or, D.: Quantifying the role of vegetation in slope stability: a case study in Tuscany (Italy). Ecol. Eng. 36(3), 285-291 (2010)

42. Fan, C.-C., Chen, Y.-W.: The effect of root architecture on the shearing resistance of root-permeated soils. Ecol. Eng. 36(6), 813-826 (2010)

43. De Baets, S., Poesen, J., Reubens, B., Wemans, K., De Baerdemaeker, J., Muys, B.: Root tensile strength and root distribution of typical Mediterranean plant species and their contribution to soil shear strength. Plant Soil 305(1), 207-226 (2008)

44. Fan, C.-C., Su, C.-F.: Role of roots in the shear strength of root-reinforced soils with high moisture content. Ecol. Eng. 33(2), 157-166 (2008)

45. Mickovski, S.B., Bengough, A.G., Bransby, M.F., Davis, M.C.R., Hallett, P.D., Sonnenberg, R.: Material stiffness, branching pattern and soil matric potential affect the pullout resistance of model root systems. Eur. J. Soil Sci. 58(6), 1471-1481 (2007)

46. Schwarz, M., Cohen, D., Or, D.: Spatial characterization of root reinforcement at stand scale: theory and case study. Geomorphology 171-172, 190-200 (2012)

47. Reubens, B., Poesen, J., Danjon, F., Geudens, G., Muys, B.: The role of fine and coarse roots in shallow slope stability and soil erosion control with a focus on root system architecture: a review. Trees 21, 385402 (2007)

48. Stokes, A., Atger, C., Bengough, A.G., Fourcaud, T., Sidle, R.C.: Desirable plant root traits for protecting natural and engineered slopes against landslides. Plant Soil 324, 1-30 (2009)

49. Bischetti, G.B., Chiaradia, E.A., Epis, T., Morlotti, E.: Root cohesion of forest species in the Italian Alps. Plant Soil 324(1), 71-89 (2009)

50. Thomas, R.E., Pollen-Bankhead, N.: Modeling root-reinforcement with a fiber-bundle model and Monte Carlo simulation. Ecol. Eng. 36(1), 47-61 (2010)

51. Yen, C.P.: Tree root patterns and erosion control. In: International Workshop on Soil Erosion and its Countermeasures, Bangkok 1987, pp. 92-111. Soil and Water Conservation Society of Thailand

52. Preti, F.: Forest protection and protection forest: tree root degradation over hydrological shallow landslides triggering. Ecol. Eng. 61, 633-645 (2013)

53. Bischetti, G.B., Bonfanti, F., Greppi, M.: Root tensile strength measurement: testing device and protocol. Quad. Idron. Mont. 21, 349-360 (2003)

54. Schuurman, J.J., Goedewaagen, M.A.: Methods for the examination of root systems and roots: methods in use at the Institute for Soil Fertility for eco-morphological root investigations. Centre for Agricultural Pub. and Documentation, Wageningen (1971) 
55. Zhang, C.-B., Chen, L.-H., Jiang, J.: Why fine tree roots are stronger than thicker roots: the role of cellulose and lignin in relation to slope stability. Geomorphology 206, 196-202 (2014)

56. Mattia, C., Bischetti, G.B., Gentile, F.: Biotechnical characteristics of root systems of typical Mediterranean species. Plant Soil 278(1), 23-32 (2005)

57. Cazzuffi, D., Crippa: Shear strength behaviour of cohesive soils reinforced with vegetation. In: 16th, Soil mechanics and geotechnical engineering, Osaka, Japan 2005, pp. 2493-2498. Millpress Science Publishers, Rotterdam

58. Comino, E., Marengo, P., Rolli, V.: Root reinforcement effect of different grass species: a comparison between experimental and models results. Soil Tillage Res. 110(1), 60-68 (2010)

59. Genet, M., Stokes, A., Fourcaud, T., Norris, J.E.: The influence of plant diversity on slope stability in a moist evergreen deciduous forest. Ecol. Eng. 36, 265-275 (2010)

60. Easson, C., Yarbrough, L.D.: The effects of riparian vegetation on bank stability. Environ. Eng. Geosci. 8(4), 247-260 (2002)

61. Abdi, M.R., Arjomand, M.A.: Pullout tests conducted on clay reinforced with geogrid encapsulated in thin layers of sand. Geotext. Geomembr. 29(6), 588-595 (2011)

62. Abdi, E., Majnounian, B., Genet, M., Rahimi, H.: Quantifying the effects of root reinforcement of Persian Ironwood (Parrotia persica) on slope stability; a case study: hillslope of Hyrcanian forests, northern Iran. Ecol. Eng. 36(10), 1409-1416 (2010)

63. Abdi, M.R., Sadrnejad, A., Arjomand, M.A.: Strength enhancement of clay by encapsulating geogrids in thin layers of sand. Geotext. Geomembr. 27(6), 447-455 (2009)

64. Simon, A., Pollen, N., Langendoen, E.: Influence of two woody riparian species on critical conditions for streambank stability: Upper Truckee River, California. J. Am. Water Resour. Assoc. 42(1), 99-113 (2006)

65. Hathaway, R.L., Penny, D.: Root strength in some Populus and Salix clones. N. Z. J. Bot. 13, 333-343 (1975)

66. Turmanina, V.: On the strength of tree roots. Bull. Mosc. Soc. Nat. 70, 36-45 (1965)

67. Commandeur, P.R., Pyles, M.R.: Modulus of elasticity and tensile strength of Douglas fir roots. Can. J. For. Res. 21, 48-52 (1991)

68. Genet, M., Stokes, A., Salin, F., Mickovski, S.B., Fourcaud, T., Dumail, J.-F., van Beek, R.: The influence of cellulose content on tensile strength in tree roots. Plant Soil 278(1), 1-9 (2005)

69. O'Neill, M.A., York, W.S.: The composition and structure of primary cell walls. In: The Plant Cell Wall. Blackwell, (2003)

70. Tiimonen, H.: Lignin characteristics and ecological interactions of PtCOMT-modified silver birch. Dissertationes Forestales 51, University of Oulu (2007)

71. Goldsmith, W.: Soil reinforcement by river plants: progress results. In: Conference on wetlands engineering and river restoration, Denver, USA 1998, pp. 301-306

72. Cazzuffi, D., Corneo, A., Crippa, E.: Slope stabilisation by perennial "Gramineae" in Southern Italy: plant growth and temporal performance. Geotech. Geol. Eng. 24, 429-447 (2006)

73. Hu, X.-S., Brierley, G., Zhu, H.-L., Li, G.-R., Fu, J.-T., Mao, X.-Q., Yu, Q., Qiao, N.: An exploratory analysis of vegetation strategies to reduce shallow landslide activity on loess hillslopes, Northeast Qinghai-Tibet Plateau, China. J. Mt. Sci. 10(4), 668-686 (2013)

74. Bache, D.H., MacAskill, I.A.: Vegetation in Civil and Landscape Engineering. Granada, London (1984)

75. Belfiore, G., Urciuoli, G.: Interpretation of the roots mechanical contribution to the soil shear strength. In: Annual Meeting of the Geotechnical Researchers Trento (2004)

76. Pollen, N.: Temporal and spatial variability in root reinforcement of streambanks: accounting for soil shear strength and moisture. Catena 69(3), 197-205 (2007)

77. Moraci, N., Recalcati, P.: Factors affecting the pullout behaviour of extruded geogrids embedded in compacted granular soil. Geotext. Geomembr. 24(4), 220-242 (2006)

78. Moraci, N., Gioffrè, D.: A simple method to evaluate the pullout resistance of extruded geogrids embedded in a compacted granular soil. Geotext. Geomembr. 24(3), 198-199 (2006)

79. Moraci, N., Cardile, G.: Cyclic pullout behaviour of geogrid embedded in compacted granular soils. In: 1st Pan American Geosynthetics Conference Cancun, Mexico, 2-5 March 2008

80. Moraci, N., Cardile, G.: Deformative behaviour of different geogrids embedded in a granular soil under monotonic and cyclic pullout loads. Geotext. Geomembr. 32, 104-110 (2012). doi:10.1016/j.geotexmem. 2011.11.001

81. Cazzuffi, D., Calvarano, L.S., Cardile, G., Moraci, N., Recalcati, P.: European experience in pullout tests: the influence of geogrid's geometry and structure on interface behaviour. Geosynthetics 29(5), 42-51 (2011) 
82. Cazzuffi, D., Moraci, N., Calvarano, L.S., Cardile, G., Gioffrè, D., Recalcati, P.: European experience in pullout tests: part 2-the influence of vertical effective stress and of geogrid length on interface behaviour under pullout conditions. Geosynthetics 32(2), 40-50 (2014)

83. Mickovski, S.B., Bransby, M.F., Bengough, A.G., Davies, A.G., Hallett, P.D.: Resistance of simple plant root system to uplift loads. Can. Geotech. J. 41(1), 78-95 (2010)

84. Wu, T.H., Beal, P.E., Lan, C.: In-situ shear test of soil-root systems. J. Geotech. Eng. 114, 1376-1394 (1988)

85. Norris, J.E., Greenwood, J.H.: In-situ shear and pull-out testing to demonstrate the enhanced shear strength of root reinforced soil. In: 8th International Symposium on Landslides, Cardiff, UK 2000, pp. 1125-1128

86. Gray, D.H., Ohashi, H.: Mechanics of fiber reinforcement in sand. J. Geotech. Eng. 109, 335-353 (1983)

87. Wu, T.H., McOrnber, R.M., Erb, R.T., Beal, P.E.: Study of soil-root interaction. J. Geotech. Eng. 114, 1351-1375 (1988)

88. Mickovski, S.B., van Beek, L.P.H.: Root morphology and effects on soil reinforcement and slope stability of young vetiver (Vetiveria zizanioides) plants grown in semi-arid climate. Plant Soil 324(1), 43-56 (2009)

89. Daniels, H.E.: The statistical theory of strength of bundles of threads. In: Royal Society London 1945, vol. 995, pp. 404-435 